\title{
Obtenção de argilas organofilicas purificadas através de tensoativos iônicos e não iônicos visando uso em fluidos de perfuração base óleo
}

\section{(Getting purified organoclays by ionic and non-ionic surfactant aiming use in oil based drilling fluids)}

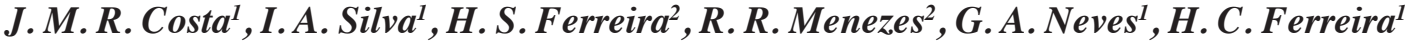 \\ ${ }^{I}$ UFCG/CCT/UAEMa, R. Aprígio Veloso 882, Campus Universitário, Campina Grande, PB \\ ${ }^{2}$ DEMat/CT/UFPB, Campus Universitário, J. Pessoa, PB \\ jullymrc@gmail.com,gelmires@dema.ufcg.edu.br,heber@dema.ufcg.edu.br
}

\begin{abstract}
Resumo
Em perfurações de petróleo sensíveis ao contato com água, torna-se necessária a utilização de fluidos de perfuração base óleo. Nestes casos, utilizam-se argilas organofílicas, que são obtidas a partir de argilas bentoníticas purificadas e tratadas com a adição de tensoativos. A utilização do hidrociclone pode representar uma ferramenta eficiente e de custo acessível para purificar argilas naturais em escala industrial. Este trabalho tem por objetivo estudar a purificação de argilas bentoníticas utilizando-se um hidrociclone, visando o desenvolvimento de argilas organofílicas para uso em fluidos de perfuração base óleo. As caracterizações das amostras das argilas estudadas - Brasgel PA e Chocolate - foram efetuadas por meio das técnicas: análise granulométrica por difração de laser, difração de raios X (DRX) e análise química por fluorescência de raios X. A caracterização das argilas organofílicas obtidas foi efetuada por meio dos seguintes métodos: DRX e por uma modificação do inchamento de Foster. Os resultados mostram que o processo de purificação foi eficiente na redução de impurezas presentes na bentonita e que a argila organofílica purificada tratada com Praepagen WB e Imidazolina Oléica Vegetal apresenta valores de inchamento de Foster em éster, óleo diesel e parafina superiores aos obtidos com argilas organofílicas sem purificação (natural), e evidenciando maior afinidade com o tensoativo Praepagen WB. Palavras-chave: hidrociclone, argilas organofílicas, fluidos de perfuração.
\end{abstract}

\begin{abstract}
Oil drilling in sensitive contact with water, becomes required the use of oil base drilling fluids. In these cases, organoclays are used, which are made from clay bentonite purified and treated with surfactants addition. The use of the hydrocyclone can be a effective tool and affordable for purifying clays in industrial scale. This work aims to study the purification of clays bentonite using a hydrocyclone, aiming to develop organoclays for use in oil base drilling fluids. The characterizations of the samples of clays Brasgel PA and Chocolate - were performed using the techniques: laser diffraction granulometric analysis, X-ray diffraction (XRD) and X-ray fluorescence chemical analysis. The characterization of organoclays obtained was accomplished through the follwing methods: XRD, TG and Foster swelling test modification. The results show that the purification process was effective in reducing impurities in the bentonite and organoclay treated with purified Praepagen WB and Imidazoline Oleic Vegetable shows Foster swelling values with, ester, diesel and paraffin higher than those obtained with organoclays without purification (natural) and showing greater affinity for the surfactant Praepagen WB.
\end{abstract}

Keywords: hydrocyclone, organophilic clays, drilling fluids.

\section{INTRODUÇÃO}

Tecnologicamente as argilas esmectíticas são geralmente denominadas de bentonitas. O termo bentonita foi aplicado às argilas plásticas inicialmente encontradas na região de Fort Benton em Wyoming (EUA), com propriedade específica e peculiar de aumentar várias vezes o seu volume inicial se umedecida com água e formar géis tixotrópicos em meios aquosos em concentrações muito baixas em torno de 2\% [1]. Atualmente, pode-se definir bentonita como sendo uma argila constituída essencialmente por um ou mais argilominerais do grupo das esmectitas especialmente a montmorilonita, não importando qual seja a sua origem geológica [2-4]. As argilas bentoníticas são constituídas por lamelas formadas por uma folha octaédrica de alumina $\left(\mathrm{Al}_{2} \mathrm{O}_{3}\right)$ entre duas folhas tetraédricas de sílica $\left(\mathrm{SiO}_{2}\right)$, nas posições octaédricas os cátions podem ser $\mathrm{Al}^{3+}, \mathrm{Mg}^{2+}$, $\mathrm{Fe}^{3+}$, e na camada tetraédrica pode ocorrer substituições isomórficas de $\mathrm{Si}^{4+}$ por $\mathrm{Al}^{3+}$. Quaisquer que sejam os cátions, as camadas estarão desequilibradas eletricamente, com uma deficiência de aproximadamente 0,66 de carga positiva por célula unitária. Essa deficiência é equilibrada principalmente por cátions hidratados fixados reversivelmente às camadas, podendo assim ser trocados por outros cátions [5, 6]. As bentonitas classificam-se em sódicas, $\mathrm{Na}^{+}$; cálcicas, $\mathrm{Ca}^{2+}$ ou magnesianas, $\mathrm{Mg}^{2+}$; e policatiônicas. A diferença no 
inchamento das sódicas e cálcicas decorre da força de atração entre camadas, que é maior na presença de $\mathrm{Ca}^{2+}$, reduzindo a quantidade de água adsorvida, e com $\mathrm{Na}^{+}$ há menor força, permitindo maior quantidade de água adsorvida entre as camadas [7]. As bentonitas apresentam amplo uso industrial, sendo utilizadas, como ligantes de areias em moldes para fundição, na descoloração de óleos, dessecantes, impermeabilizante de barragens, em fluidos ou lamas de perfuração, etc. [6, 8]. Quando utilizadas em fluidos de perfuração possuem importantes funções durante toda a perfuração, como: redução das infiltrações nas formações permeáveis, formação de membrana de baixa permeabilidade (reboco), estabilização do poço, etc. [9].

As argilas esmectíticas, quando dispersas em meio aquoso podem tornar-se organofílicas com a adição de tensoativos [10-12]. Os tensoativos iônicos utilizados na modificação possuem um ou dois grupos de hidrocarbonetos de cadeia longa (derivados geralmente de ácidos graxos) ligados diretamente a um átomo de nitrogênio onde se situa a parte catiônica da molécula. Ao adicionar esses sais às dispersões aquosas de argilas esmectíticas, esses cátions orgânicos substituem os cátions sódio que são facilmente trocáveis; assim, os cátions quaternários de amônio se acomodam entre as camadas 2:1 do argilomineral, tornando-a organofílicas $[2,12]$. No caso dos tensoativos não-iônicos, o mecanismo de organofilização é baseado em fenômenos de adsorção, não havendo a necessidade da prévia transformação da argila esmectítica policatiônica em sódica, podendo-se, portanto, proceder no processo de organofilização com as argilas policatiônicas [13-15]. Após a organofilização, as argilas apresentam a propriedade de se expandir em dispersantes orgânicos e têm um caráter hidrofóbico bastante elevado. O tipo de bentonita e tensoativo e o processo de obtenção da argila organofílica irão definir os meios orgânicos nos quais as argilas irão expandir-se [16].

A preferência quanto ao uso das argilas bentoníticas na síntese de argilas organofílicas deve-se às pequenas dimensões dos cristais; isso faz com que as reações de intercalação sejam rápidas e que as reações governadas por troca de cátions e adsorção sejam 100\% completas [1]. As argilas organofílicas possuem um grande número de aplicações devido às suas características peculiares. São amplamente utilizadas nas indústrias como componentes tixotrópicos de fluidos de perfuração de poços de petróleo à base de óleo; nas indústrias de fundição de metais, lubrificantes, tintas, adesivos e cosméticos, e no controle do meio-ambiente [3]. Recentemente as argilas organofílicas estão sendo estudadas como aditivos de desempenho na obtenção de nanocompósitos visando promover mudanças nas propriedades mecânicas, físicas e químicas de matrizes poliméricas [2].

Os hidrociclones são equipamentos que promovem a separação do tipo sólido-líquido e podem representar uma ferramenta bastante eficiente e de custo acessível para a purificação de argilas naturais em escala industrial, separando-se as frações mais grosseiras, relativas à presença principalmente de minerais acessórios, das frações mais finas, constituídas pelo argilomineral. O hidrociclone consiste de uma parte cônica ligada a uma parte cilíndrica, na qual existe uma entrada tangencial para a suspensão de alimentação. A parte superior do hidrociclone apresenta um tubo para a saída da suspensão diluída ("overflow") e na parte inferior há um orifício de saída da suspensão concentrada ("underflow"). O princípio de funcionamento de um hidrociclone deve-se à alimentação tangencial de uma suspensão sólido-líquido na região cilíndrica do equipamento, e devido à força centrífuga e ao formato do equipamento, tem-se a formação de um vórtex descendente, fazendo com que as partículas maiores e mais densas sejam projetadas contra a parede, sendo então arrastadas até a saída inferior do mesmo (apex). As partículas menores e de menor densidade são então arrastadas para o centro do equipamento formando um vórtex ascendente, saindo por um orifício superior (vórtex), Fig. 1 [17, 18].

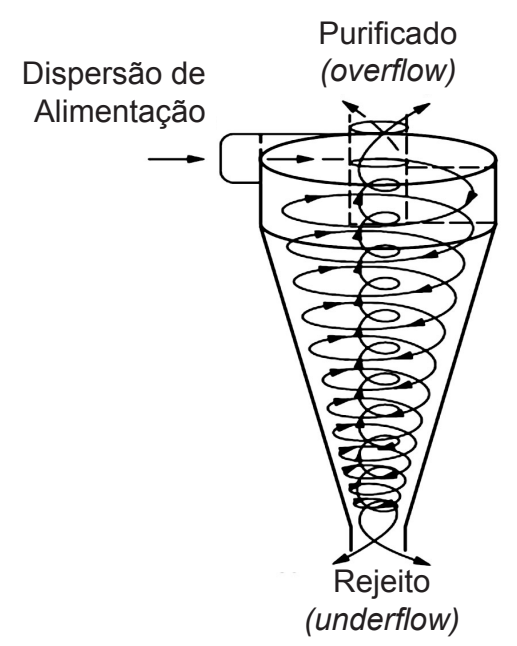

Figura 1: Esquema típico de um hidrociclone e principio de funcionamento.

[Figure 1: Typical hydrocyclone scheme and operating principle.]

Este trabalho tem como objetivo estudar a purificação de argilas bentoníticas utilizando-se um hidrociclone, visando o desenvolvimento de argilas organofílicas purificadas a partir de tensoativos iônicos e não iônicos para uso em fluidos de perfuração base óleo, tendo como agente dispersante bases orgânicas tais como parafina, éster e óleo diesel.

\section{MATERIAIS E MÉTODOS}

Foram utilizadas as argilas do tipo: Brasgel PA bentonita sódica industrializada fornecida pela Bentonit União Nordeste, localizada na cidade de Boa Vista, PB; Chocolate - argila bentonítica natural, policatiônica, proveniente da Mina Bravo, localizada no Município de Boa Vista, PB. Foi escolhida em virtude de apresentar excelentes resultados quando sua transformação em sódica para uso em fluidos de perfuração à base de água [16].

O tensoativo iônico utilizado foi o Praepagen WB e o tensoativo não iônico foi a Imidazolina Oléica Vegetal. E 
os meios líquidos orgânicos dispersantes foram parafina, éster e óleo diesel. Estes reagentes foram fornecidos pela Oxiteno, S. Paulo, SP.

A metodologia utilizada para o desenvolvimento da pesquisa consiste nas etapas descritas abaixo.

Para a caracterização das argilas foram utilizadas as seguintes técnicas: análise granulométrica por difração de laser, AG, a argila bentonítica foi passada em peneira ABNT $200(0,074 \mathrm{~mm})$, e dispersa em $250 \mathrm{~mL}$ de água destilada em agitador Hamilton Beach N5000 a velocidade de $17.000 \mathrm{rpm}$ por $10 \mathrm{~min}$, em seguida esta dispersão foi colocada em um equipamento Cilas 1064, em modo úmido, até atingir a concentração ideal que é de 170 unidades de difração/área de incidência [16].

As análises químicas por fluorescência de raios $\mathrm{X}$ foram efetuadas em equipamento EDX 720 Shimadzu, com as amostras de argila passadas em peneira ABNT 200 $(0,074 \mathrm{~mm})[16]$.

A difração de raios X, DRX, dos sólidos foi realizada em um equipamento Shimadzu XRD-6000. A radiação utilizada foi Cuk $\alpha$ (40 kV/30 mA); a velocidade do goniômetro foi de $2 \%$ min e passo de $0,02^{\circ}$ e varredura de $2^{\circ}$ até $30^{\circ}[16]$.

As análises termogravimétrica (TG) e termodiferencial (ATD) foram obtidas em um sistema de análises térmicas RB-3000 BP Engenharia, com taxa de aquecimento $12,5^{\circ} \mathrm{C} / \mathrm{min}$. A temperatura máxima para ambos os casos foi $1000{ }^{\circ} \mathrm{C}$ e o padrão utilizado na ATD foi óxido de alumínio $\left(\mathrm{Al}_{2} \mathrm{O}_{3}\right)$ calcinado [16].

A caracterização das argilas organofílicas obtidas foi efetuada por meio dos seguintes métodos: difração de raios $\mathrm{X}$ e por uma modificação do inchamento de Foster em

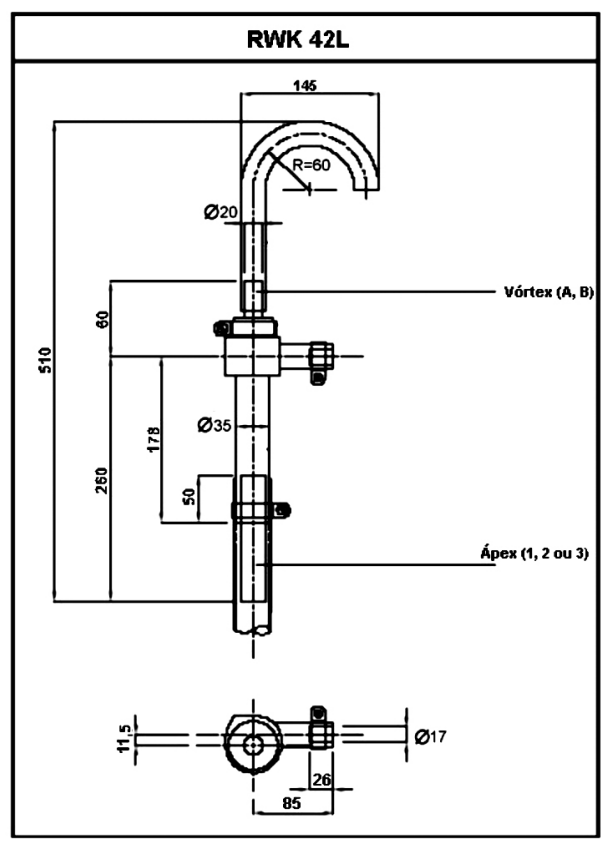

Figura 2: Representação esquemática do hidrociclone utilizado. [Figure 2: Schematic representation of the used hydrocyclone.]
Tabela I - Dimensões dos orifícios utilizados no hidrociclone. [Table I - Hidrocyclone dimensions of holes used.]

\begin{tabular}{ccccc}
\hline \multicolumn{2}{c}{ Vórtex } & \multicolumn{4}{c}{ Apex } \\
(Diâmetro interno) & \multicolumn{3}{c}{ (Diâmetro interno) } \\
$\mathrm{A}$ & $\mathrm{B}$ & 1 & 2 & 3 \\
\hline $5 \mathrm{~mm}$ & $6 \mathrm{~mm}$ & $4 \mathrm{~mm}$ & $3 \mathrm{~mm}$ & $5 \mathrm{~mm}$ \\
\hline
\end{tabular}

éster, parafina e óleo diesel [18, 19].

Processo de preparação e purificação de argilas: cada amostra de argila seca foi dispersa numa concentração de $4 \%$ em massa, num volume de $30 \mathrm{~L}$ mantida sob agitação por um período de $24 \mathrm{~h}$ em temperatura ambiente. Após esse período, a dispersão é bombeada com o auxilio de uma bomba centrifuga para o hidrociclone onde ocorre o processo de separação do fluxo em "overflow" e "underflow". O "underflow" é colhido na parte inferior, ápex, (rejeito), e o "overflow" na parte superior, vórtex, (purificado). A Fig. 2 o esquema técnico do hidrociclone. Foi utilizado um hidrociclone EWK 42L Netzsch AWK, Alemanha, com corte na fração de 2 a $5 \mu \mathrm{m}$.

Os orifícios utilizados, o vórtex e o apex, podem ser variados, essa variação resulta na modificação da concentração e da vazão. Serão utilizadas todas as combinações, escolhendo-se assim os melhores resultados visando a otimização do processo de separação granulométrica. As dimensões do vórtex e do apex podem ser vistas na Tabela I.

\section{Processo de organofilização}

Foram efetuados dois processos de organofilização, um em escala de bancada e outro em escala piloto, mas com os mesmos componentes e nas mesmas proporções.

A Chocolate, por ser uma argila bentonítica natural, policatiônica, necessita de sua transformação em sódica para ser submetida ao processo de organofilização. O processo de tratamento foi realizado segundo o procedimento descrito a seguir: as dispersões da argila Chocolate foram tratadas com uma solução de carbonato de sódio $\left(\mathrm{Na}_{2} \mathrm{CO}_{3}\right)$ com concentração de $5,6 \mathrm{~g} / \mathrm{mL}$ à proporção de $100 \mathrm{meq} / 100$ $\mathrm{g}$ de argila seca. Para tanto, as dispersões foram mantidas em banho-maria e submetidas à agitação vigorosa a 17.000 rpm durante $2 \mathrm{~h}$, adicionando o teor de $\mathrm{Na}_{2} \mathrm{CO}_{3}$ e agitando por mais $20 \mathrm{~min}$. As dispersões tratadas permaneceram em repouso por 1 dia. Já a Brasgel PA por ser uma argila bentonítica sódica industrializada, não há necessidade de tratamento transformação para forma sódica.

O processo de organofilização foi realizado segundo o procedimento descrito a seguir: as dispersões de argila foram preparadas com velocidade de agitação de $1750 \mathrm{rpm}$, adicionando-se tensoativo iônico Praepagen WB, ou o tensoativo não iônico Imidazolina Oléica Vegetal, no teor de $60 \%$ em relação ao teor de argila seca, mantendo a agitação por 20 min. Foram selecionados para a organofilização as quatro melhores configurações do hidrociclone que conduzem a melhor eficiência no processo de purificação. 


\section{Inchamento de Foster}

Os testes de inchamento de Foster foram realizados segundo indicações das Refs. [18, 20]. As medidas do inchamento de Foster foram realizadas em parafina, éster e óleo diesel. Em uma proveta, foi adicionado lentamente argila bentonítica organofílica ao dispersante a ser estudado. O sistema foi deixado em repouso por $24 \mathrm{~h}$ e então foi efetuada a leitura do inchamento "sem agitação". Depois a dispersão foi mecanicamente agitada, sendo em seguida o sistema novamente deixado em repouso por mais $24 \mathrm{~h}$ e então foi efetuada a leitura do inchamento "com agitação".

Valores iguais ou inferiores a $2 \mathrm{~mL} / \mathrm{g}$ foram considerados como "não inchamento"; de 3 a $5 \mathrm{~mL} / \mathrm{g}$ como "inchamento baixo"; de 6 a $8 \mathrm{~mL} / \mathrm{g}$ como "inchamento médio" e acima de $8 \mathrm{~mL} / \mathrm{g}$ como "inchamento alto". Este método mostra a compatibilidade do meio estudado com as argilas organofílicas obtidas com os diversos tensoativos $[20]$.

\section{Preparação dos fluidos não aquosos}

Por fim, os fluidos de perfuração não aquosos foram preparados da seguinte forma: em um copo do agitador Hamilton Beach N5000 adicionou-se $336 \mathrm{~mL}$ do meio líquido orgânico que é a base do fluido e sob agitação contínua adicionou-se $84 \mathrm{~mL}$ de uma solução saturada de $\mathrm{NaCl}(0,395 \mathrm{~g} / \mathrm{mL})$ mantendo-se agitação por $5 \mathrm{~min}$. Esta solução de $\mathrm{NaCl}$ visa simular a contaminação da água do mar, que ocorre em situações reais de perfuração em plataformas marítimas. Esta emulsão é chamada de lama base. Em seguida foi adicionada a argila organofílica nos teores de 2,4 g, $6 \mathrm{~g}$, 9,6 g e 13,2 g de argila organofílica, a agitação foi mantida por $15 \mathrm{~min}$. Depois de preparado, o fluido foi depositado em um "roller over" (estufa rotativa) aquecida a $66^{\circ} \mathrm{C}$ por $16 \mathrm{~h}$ para ocorrer o envelhecimento [21].

\section{Viscosidade aparente dos fluidos não aquosos}

Após $16 \mathrm{~h}$ de envelhecimento o fluido foi retirado e agitado por mais 5 min no agitador Hamilton Beach N5000 a $17000 \mathrm{rpm}$. Em seguida, a dispersão foi colocada em um viscosímetro FANN 35A por 2 min e então foi medida a deflexão do ponteiro, a $600 \mathrm{rpm}$, e calculada a viscosidade aparente (VA). Esperou-se mais $15 \mathrm{~s}$ e então foi medida a deflexão do ponteiro, a $300 \mathrm{rpm}$, e calculada a viscosidade plástica (VP). O valor de VA foi comparado com o valor normatizado [21,22]. Essa análise teve por objetivo avaliar a influência do processo de purificação no comportamento reológico das argilas e sua adequação ou não aos limites da Petrobrás para fluidos de perfuração à base água.

\section{Normatização}

Quando obtidos a partir de argilas organofílicas, os fluidos base óleo tem valores de viscosidade aparente normatizados para o meio dispersante óleo diesel, pela Petrobrás [21]. A argila organofílica deve-se apresentar isenta de aglomerados e materiais estranhos e cumprir com os requisitos contidos da Tabela II. Para os meios orgânicos éster e parafina, vão servir como subsídio para normas futuras da Petrobrás.

Tabela II - Requisitos mínimos de viscosidade aparente para fluidos de perfuração base óleo [21].

[Table II - Oil based drilling fluids minimum apparent viscosity [21].]

\begin{tabular}{cc}
\hline $\begin{array}{c}\text { Massa do produto } \\
(\mathrm{g} / 420 \mathrm{~mL} \text { de lama-base })\end{array}$ & $\begin{array}{c}\text { Viscosidade aparente } \\
(\mathrm{cP}) \text { mínima }\end{array}$ \\
\hline 2,4 & 6,0 \\
6,0 & 8,0 \\
9,6 & 11,0 \\
13,2 & 16,0 \\
\hline
\end{tabular}

\section{RESULTADOS E DISCUSSÄO}

Nas Tabelas III e IV são apresentados resultados das análises granulométricas das argilas Brasgel PA e Chocolate, após terem sido passadas em peneira ABNT $200(0,074 \mathrm{~mm})$ e dispersas em água. A argila Brasgel PA (Tabelas III e IV) apresenta um diâmetro médio de 5,93 $\mu \mathrm{m}$, diâmetro a 50\% de 4,49 $\mu \mathrm{m}$, maior concentração de partículas entre $4 \mu \mathrm{m}$ e $8 \mu \mathrm{m}$ e volume acumulado com diâmetro médio abaixo de $2 \mu \mathrm{m}$ de $24,61 \%$, que corresponde à fração argila, e 73,48\% correspondente ao teor de silte. Analisando as Tabelas III e IV, referente à argila Chocolate, observa-se um diâmetro médio das partículas de 12,47 $\mu \mathrm{m}$, observa-se cerca de $8,22 \%$ do volume acumulado com diâmetro médio abaixo de $2 \mu \mathrm{m}$, que corresponde a fração argila, diâmetro a $50 \%$ de $10,19 \mu \mathrm{m}$ e uma maior concentração de partículas entre 9 e $11 \mu \mathrm{m}, \mathrm{e} 72,78 \%$ correspondente ao teor de silte.

Na Tabela V são apresentadas as composições químicas das argilas Brasgel PA e Chocolate. As argilas possuem composição química típica das argilas bentoníticas $[1,7,19$, $21]$.

A Fig. 3 mostra os difratogramas de raios $\mathrm{X}$ das argilas Brasgel PA e Chocolate. Observa-se o argilomineral esmectítico, caracterizado pelas distâncias interplanares $12,77 \AA$ e 4,44 ̊, quartzo, caracterizado pelas distâncias interplanares 4,27 $\AA$ e 3,36 A. A presença do argilomineral esmectítico foi confirmada pelo uso do etilenoglicol. O argilomineral esmectítico é caracterizado pelas distâncias interplanares 14,95 $\AA$ e 4,45 , presença de quartzo, caracterizado apenas pelas distâncias interplanares 4,25 e 3,34 A. De forma geral as argilas possuem difratogramas típicos das argilas bentoníticas $[1,7,21]$.

A Fig. 4 apresenta as curvas de análises termogravimétricas e térmicas diferenciais das argilas bentoníticas Brasgel PA e Chocolate. Na curva de ATD da argila Brasgel PA foram observadas as seguintes 
transformações térmicas: grande banda endotérmica com máximo em $155^{\circ} \mathrm{C}$, característica da presença de água adsorvida; banda endotérmica com máximo em $556{ }^{\circ} \mathrm{C}$, característica da presença de hidroxilas da folha octaédrica; banda endotérmica com máximo em $801{ }^{\circ} \mathrm{C}$, característica da destruição do retículo cristalino, e banda exotérmica com máximo em $901{ }^{\circ} \mathrm{C}$, característica da nucleação de mulita com liberação de quartzo $\beta$ a partir da estrutura amorfa criada anteriormente. Para argila Brasgel PA, a perda total de massa foi de $19,45 \%$.

Foram observadas as seguintes transformações térmicas: grande banda endotérmica com máximo em $150{ }^{\circ} \mathrm{C}$, característica de água livre e adsorvida; banda endotérmica com máximo em $572{ }^{\circ} \mathrm{C}$, característica de hidroxilas da folha octaédrica; banda endotérmica com máximo em $864^{\circ} \mathrm{C}$, característica da destruição do retículo cristalino e banda exotérmica com máximo em $903{ }^{\circ} \mathrm{C}$ da nucleação da mulita com liberação de quartzo $\beta$ a partir da estrutura amorfa citada anteriormente. Analisou-se as curvas de TG para a argila Chocolate, foram observados os eventos característicos da perda de água e perda de hidroxilas e uma perda total de massa de $26 \%$.

Foram observadas as seguintes transformações térmicas: grande banda endotérmica com máximo em $150{ }^{\circ} \mathrm{C}$, característica de água livre e adsorvida; banda endotérmica com máximo em $572{ }^{\circ} \mathrm{C}$, característica de hidroxilas da folha octaédrica; banda endotérmica com máximo em $864^{\circ} \mathrm{C}$, característica da destruição do retículo cristalino e banda exotérmica com máximo em $903{ }^{\circ} \mathrm{C}$ da nucleação da mulita com liberação de quartzo $\beta$ a partir da estrutura amorfa citada anteriormente. Analisou-se as curvas de TG para a argila Chocolate, foram observados os eventos característicos da perda de água e perda de hidroxilas e uma perda total de massa de $26 \%$.

As Tabelas VI e VII apresentam os resultados das análises granulométricas das amostras de Brasgel PA purificadas ("overflow") e dos rejeitos e ("underflow").

Analisando as amostras (a) A1_OF; (b) A1_UF; (c) B1_OF; (d) B1_UF, verifica-se o diâmetro médio das partículas de (a) $5,57 \mu \mathrm{m}$; (b) $27,25 \mu \mathrm{m}$; (c) $5,41 \mu \mathrm{m}$; (d) $34,91 \mu \mathrm{m}$. Observa-se cerca de (a) $25,09 \%$; (b) $11,58 \%$; (c) $26,26 \%$; (d) $9,99 \%$ da massa acumulada com diâmetro médio equivalente abaixo de $2 \mu \mathrm{m}$, que corresponde a fração argila, diâmetro a $50 \%$ de (a) 4,32 $\mu \mathrm{m}$; (b) 11,58 $\mu \mathrm{m}$; (c) $4,17 \mu \mathrm{m}$; (d) $17,05 \mu \mathrm{m}$. Podemos observar claramente a redução do tamanho médio equivalente das partículas após o processo de hidrociclonagem tanto para o conjunto A1 como para o B1.

Analisando as amostras (a) A2_OF; (b) A2_UF; (c) B2_OF; (d) B2_UF verifica-se o diâmetro médio das partículas de (a) $5,92 \mu \mathrm{m}$; (b) $5,80 \mu \mathrm{m}$; (c) $5,71 \mu \mathrm{m}$; (d) $27,34 \mu \mathrm{m}$. Observa-se cerca de (a) $25,27 \%$; (b) $25,63 \%$; (c) $25,27 \%$; (d) $14,94 \%$ da massa acumulada com diâmetro médio equivalente abaixo de $2 \mu \mathrm{m}$, que corresponde a fração argila, diâmetro a $50 \%$ de (a) 4,31 $\mu \mathrm{m}$; (b) 4,32 $\mu \mathrm{m}$; (c) $4,32 \mu \mathrm{m}$; (d) $9,29 \mu \mathrm{m}$. Podemos observar que apenas o conjunto B2 foi capaz de promover separação granulométrica. O conjunto A2 apresenta resultados

Tabela III - Análise granulométrica por difração de laser (AG) das argilas Brasgel PA e Chocolate.

[Table III - Chocolate and Brasgel PA clays particle size analysis by laser diffraction (GA).]

\begin{tabular}{ccccc}
\hline Amostra & $\begin{array}{c}\text { Diâmetro médio } \\
(\mu \mathrm{m})\end{array}$ & $\begin{array}{c}\text { Diâmetro a 50\% } \\
(\mu \mathrm{m})\end{array}$ & $\begin{array}{c}\text { Volume acumulado } \\
\text { abaixo de 2 } \mu \mathrm{m}(\%)\end{array}$ & $\begin{array}{c}\text { Faixa de concentração de } \\
\text { partículas }(\mu \mathrm{m})\end{array}$ \\
\hline Brasgel PA & 5,93 & 4,49 & 24,61 & $4-8$ \\
Chocolate & 12,47 & 10,19 & 8,22 & $9-11$ \\
\hline
\end{tabular}

Tabela IV - Distribuição granulométrica resumida das argilas Brasgel PA e Chocolate. [Table IV - Particle size distribution summary of Brasgel PA and Chocolate clays.]

\begin{tabular}{cccc}
\hline Amostra & Argila $(\%)(\mathrm{x}<2 \mu \mathrm{m})$ & Silte $(\%)(2 \mu \mathrm{m}<\mathrm{x}<20 \mu \mathrm{m})$ & Areia $(\%)(\mathrm{x}>20 \mu \mathrm{m})$ \\
\hline Brasgel PA & 24,61 & 73,48 & 1,91 \\
Chocolate & 8,22 & 72,78 & 19,00 \\
\hline
\end{tabular}

Tabela V - Composição química da argila Brasgel PA e Chocolate. [Table V-Chocolate and Brasgel PA clays chemical composition.]

\begin{tabular}{cccccccccc}
\hline \multirow{2}{*}{ Amostra } & \multicolumn{8}{c}{ Composição Química (\%) } \\
& $\mathrm{SiO}_{2}$ & $\mathrm{Al}_{2} \mathrm{O}_{3}$ & $\mathrm{Fe}_{2} \mathrm{O}_{3}$ & $\mathrm{CaO}$ & $\mathrm{MgO}$ & $\mathrm{Na}_{2} \mathrm{O}$ & $\mathrm{K}_{2} \mathrm{O}$ & Outros $^{\mathrm{a}}$ & $\mathrm{PR}^{\mathrm{b}}$ \\
\hline Brasgel PA & 62,33 & 16,45 & 7,76 & 1,26 & 2,09 & 1,65 & 0,52 & 1,18 & 6,61 \\
Chocolate & 59,77 & 17,31 & 10,37 & 0,30 & 2,21 & - & 0,21 & 1,07 & 8,72 \\
\hline
\end{tabular}

${ }^{a}$ Outros óxidos, ${ }^{b}$ Perda ao Rubro, determinada por calcinação em amostras secas a $110^{\circ} \mathrm{C}$. 


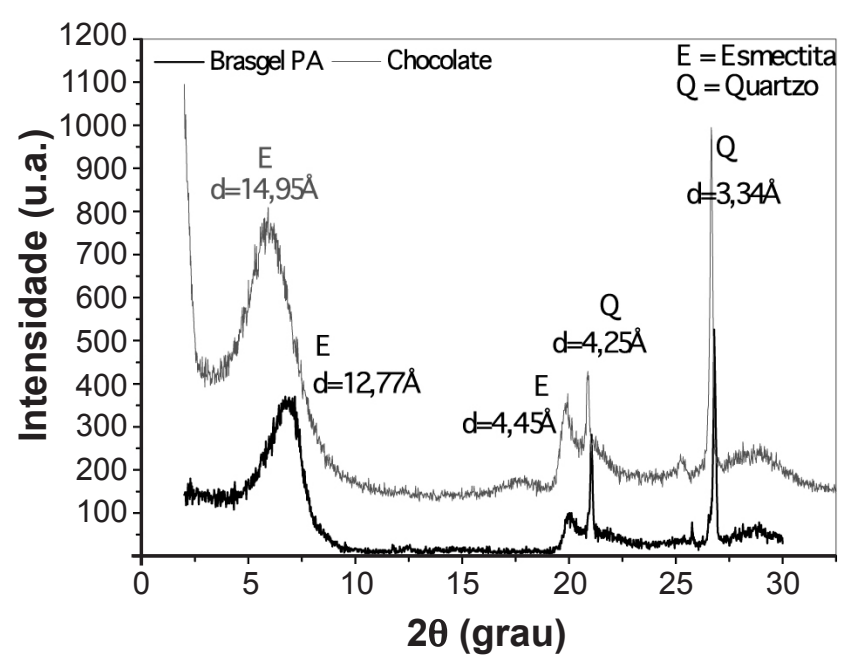

Figura 3: Difração de raios X das argilas Brasgel PA (preto) e Chocolate (cinza).

[Figure 3: Brasgel PA (black) and Chocolate (gray) clays X-ray diffraction pattern.]

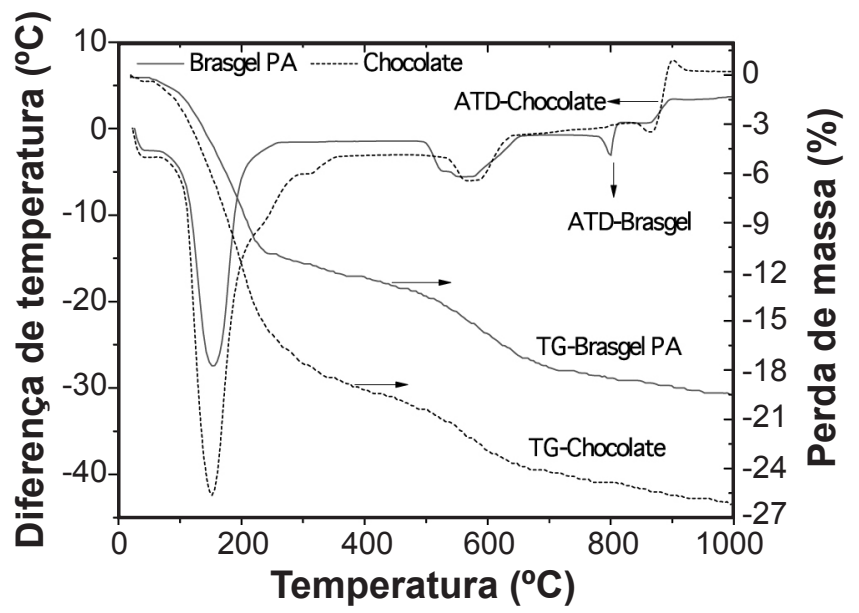

Figura 4: Curvas de análises termogravimétricas e térmicas diferenciais das argilas bentoníticas Brasgel PA e Chocolate secas a $60{ }^{\circ} \mathrm{C}$.

[Figure 4: Differential thermal and thermogravimetric analysis curves of Brasgel PA and Chocolate bentonite clays dried at $60{ }^{\circ} \mathrm{C}$.]

iguais tanto para o "overflow" quanto para o "underflow". Analisando as amostras (a) A3_OF; (b) A3_UF; (c) B3_OF; (d) B3_UF verifica-se o diâmetro médio das partículas de (a) $6,32 \mu \mathrm{m}$; (b) $6,19 \mu \mathrm{m}$; (c) $6,20 \mu \mathrm{m}$; (d) $5,90 \mu \mathrm{m}$. Observa-se cerca de (a) $23,55 \%$; (b) $24,96 \%$; (c) $24,83 \%$; (d) $25,14 \%$ da massa acumulada com diâmetro médio equivalente abaixo de $2 \mu \mathrm{m}$, que corresponde a fração argila, diâmetro a $50 \%$

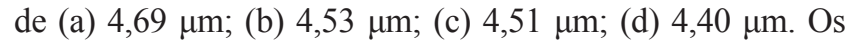
conjuntos A3 e B3 mostram-se pouco eficientes no processo de purificação visto a similaridade entre o "overflow" e "underflow".

As Tabelas VIII e IX apresentam os resultados das análises granulométricas das amostras de Chocolate purificadas ("overflow") e dos rejeitos e ("underflow").

Analisando as amostras (a) A1_OF; (b) A1_UF; (c)
Tabela VI - Análise granulométrica por difração de laser (AG) da argila Brasgel PA (purificadas e rejeitos).

[Table VI - Particle size distribution by laser diffraction (GA) of Brasgel PA clay (purified and rejects).]

\begin{tabular}{cccc}
\hline $\begin{array}{c}\text { Amostra } \\
\text { Brasgel }\end{array}$ & $\begin{array}{c}\text { Diâmetro } \\
\text { médio } \\
(\mu \mathrm{m})\end{array}$ & $\begin{array}{c}\text { Diâmetro a } \\
50 \%(\mu \mathrm{m})\end{array}$ & $\begin{array}{c}\text { Volume } \\
\text { acumulado } \\
\text { abaixo de } \\
2 \mu \mathrm{m}(\%)\end{array}$ \\
\hline A1OF & 5,57 & 4,32 & 25,09 \\
A2OF & 5,92 & 4,31 & 25,27 \\
A3OF & 6,32 & 4,69 & 23,55 \\
B1OF & 5,41 & 4,17 & 26,26 \\
B2OF & 5,71 & 4,32 & 25,27 \\
B3OF & 6,20 & 4,51 & 24,83 \\
A1UF & 27,25 & 11,58 & 11,58 \\
A2UF & 5,80 & 4,32 & 25,63 \\
A3UF & 6,19 & 4,53 & 24,96 \\
B1UF & 34,91 & 17,05 & 9,99 \\
B2UF & 27,34 & 9,29 & 14,94 \\
B3UF & 5,90 & 4,40 & 25,14 \\
\hline
\end{tabular}

Tabela VII - Análise granulométrica por tamanho de partículas da argila Brasgel PA (purificadas e rejeitos).

[Table VII - Particle size distribution summary by laser diffraction (GA) of Brasgel PA clay (purified and rejects).]

\begin{tabular}{cccc}
\hline $\begin{array}{c}\text { Amostra } \\
\text { Brasgel }\end{array}$ & $\begin{array}{c}\text { Argila }(\%) \\
(\mathrm{x}<2 \mu \mathrm{m})\end{array}$ & $\begin{array}{c}\text { Silte }(\%) \\
(2 \mu \mathrm{m}<\mathrm{x}<20 \mu \mathrm{m})\end{array}$ & $\begin{array}{c}\text { Areia }(\%) \\
(\mathrm{x}>20 \mu \mathrm{m})\end{array}$ \\
\hline A1OF & 25,09 & 73,69 & 1,22 \\
A2OF & 25,27 & 71,45 & 3,28 \\
A3OF & 23,55 & 73,12 & 3,33 \\
B1OF & 26,26 & 72,80 & 0,94 \\
B2OF & 25,27 & 72,87 & 1,86 \\
B3OF & 24,83 & 71,55 & 3,62 \\
A1UF & 11,58 & 51,03 & 37,39 \\
A2UF & 25,63 & 72,35 & 2,02 \\
A3UF & 24,96 & 71,58 & 3,46 \\
B1UF & 9,99 & 43,54 & 46,47 \\
B2UF & 14,94 & 50,90 & 35,16 \\
B3UF & 25,14 & 72,74 & 2,12 \\
\hline
\end{tabular}

B1_OF; (d) B1_UF verifica-se o diâmetro médio das partículas de (a) $8,84 \mu \mathrm{m}$; (b) $13,52 \mu \mathrm{m}$; (c) $9,14 \mu \mathrm{m}$; (d) $13,43 \mu \mathrm{m}$. Observa-se cerca de (a) $11,70 \%$; (b) $6,64 \%$; (c) $9,71 \%$; (d) $6,03 \%$ da massa acumulada com diâmetro médio equivalente abaixo de $2 \mu \mathrm{m}$, que corresponde a fração argila, diâmetro a $50 \%$ de (a) $7,53 \mu \mathrm{m}$; (b) 8,19 $\mu \mathrm{m}$; (c) $11,88 \mu \mathrm{m}$; (d) $11,88 \mu \mathrm{m}$. Podemos observar de forma clara a redução do tamanho médio equivalente das partículas após o processo de hidrociclonagem tanto para o conjunto A1 como para o B1. Analisando as amostras (a) A2_OF; (b) A2_UF; (c) B2_OF; (d) B2_UF verificase o diâmetro médio das partículas de (a) $8,70 \mu \mathrm{m}$; (b) $15,20 \mu \mathrm{m}$; (c) $9,86 \mu \mathrm{m}$; (d) $13,08 \mu \mathrm{m}$. Observa-se cerca de (a) $12,71 \%$; (b) $7,13 \%$; (c) $9,69 \%$; (d) $5,54 \%$ da massa acumulada com diâmetro médio equivalente abaixo de $2 \mu \mathrm{m}$, que corresponde a fração argila, diâmetro a $50 \%$ 
Tabela VIII - Análise granulométrica por difração de laser (AG) da argila Chocolate (purificadas e rejeitos).

[Table VIII - Particle size distribution by laser diffraction (GA) of Chocolate clay (purified and rejects).]

\begin{tabular}{cccc}
\hline $\begin{array}{c}\text { Amostra } \\
\text { Chocolate }\end{array}$ & $\begin{array}{c}\text { Diâmetro } \\
\text { médio } \\
(\mu \mathrm{m})\end{array}$ & $\begin{array}{c}\text { Diâmetro a } \\
50 \%(\mu \mathrm{m})\end{array}$ & $\begin{array}{c}\text { Volume } \\
\text { acumulado } \\
\text { abaixo de } \\
2 \mu \mathrm{m}(\%)\end{array}$ \\
\hline A1OF & 8,84 & 7,53 & 11,70 \\
A2OF & 8,70 & 7,23 & 12,71 \\
A3OF & 8,06 & 6,67 & 13,80 \\
B1OF & 9,14 & 8,19 & 9,71 \\
B2OF & 9,86 & 8,64 & 9,69 \\
B3OF & 8,82 & 7,68 & 11,49 \\
A1UF & 13,52 & 11,74 & 6,64 \\
A2UF & 15,20 & 12,44 & 7,13 \\
A3UF & 12,64 & 10,23 & 8,47 \\
B1UF & 13,43 & 11,88 & 6,03 \\
B2UF & 13,08 & 12,08 & 5,54 \\
B3UF & 13,09 & 12,05 & 5,73 \\
\hline
\end{tabular}

Tabela IX - Distribuição granulométrica por difração a laser (AG) da argila Chocolate (purificadas e rejeitos).

[Table IX - Chocolate clay (purified and rejects) particle size analysis by laser diffraction (GA).]

\begin{tabular}{cccc}
\hline $\begin{array}{c}\text { Amostra } \\
\text { Cocolate }\end{array}$ & $\begin{array}{c}\text { Argila }(\%) \\
(\mathrm{x}<2 \mu \mathrm{m})\end{array}$ & $\begin{array}{c}\text { Silte }(\%) \\
(2 \mu \mathrm{m}<\mathrm{x}<20 \mu \mathrm{m})\end{array}$ & $\begin{array}{c}\text { Areia }(\%) \\
(\mathrm{x}>20 \mu \mathrm{m})\end{array}$ \\
\hline A1OF & 11,70 & 82,21 & 6,09 \\
A2OF & 12,71 & 80,78 & 6,51 \\
A3OF & 13,80 & 81,38 & 4,82 \\
B1OF & 9,71 & 85,07 & 5,22 \\
B2OF & 9,69 & 81,70 & 8,61 \\
B3OF & 11,49 & 83,34 & 5,17 \\
A1UF & 6,64 & 70,94 & 22,42 \\
A2UF & 7,13 & 64,87 & 28,0 \\
A3UF & 8,47 & 71,56 & 19,97 \\
B1UF & 6,03 & 72,45 & 21,52 \\
B2UF & 5,54 & 74,68 & 19,78 \\
B3UF & 5,73 & 74,02 & 20,25 \\
\hline
\end{tabular}

de (a) $7,23 \mu \mathrm{m}$; (b) $12,44 \mu \mathrm{m}$; (c) $8,64 \mu \mathrm{m}$; (d) $12,08 \mu \mathrm{m}$. Podemos observar que tanto o conjunto A2 como o B2 foram capazes de promover separação granulométrica. Analisando as amostras (a) A3_OF; (b) A3_UF; (c) B3_OF; (d) B3_UF verifica-se o diâmetro médio das partículas de (a) $8,06 \mu \mathrm{m}$; (b) $12,64 \mu \mathrm{m}$; (c) $8,82 \mu \mathrm{m}$; (d) $13,09 \mu \mathrm{m}$. Observa-se cerca de (a) $13,80 \%$; (b) $8,47 \%$; (c) $11,49 \%$; (d) $5,73 \%$ da massa acumulada com diâmetro médio equivalente abaixo de 2 $\mu \mathrm{m}$, que corresponde a fração argila, diâmetro a $50 \%$ de (a) $6,67 \mu \mathrm{m}$; (b) $10,23 \mu \mathrm{m}$; (c) $7,68 \mu \mathrm{m}$; (d) $12,05 \mu \mathrm{m}$. Os conjuntos A3 e B3 foram capazes de promover separação granulométrica.

As Figs. 5 e 6 apresentam os resultados de difração de raios X da argila Brasgel PA após hidrociclonagem. Pelo difratograma da argila bentonítica, Fig. 5a, observa-
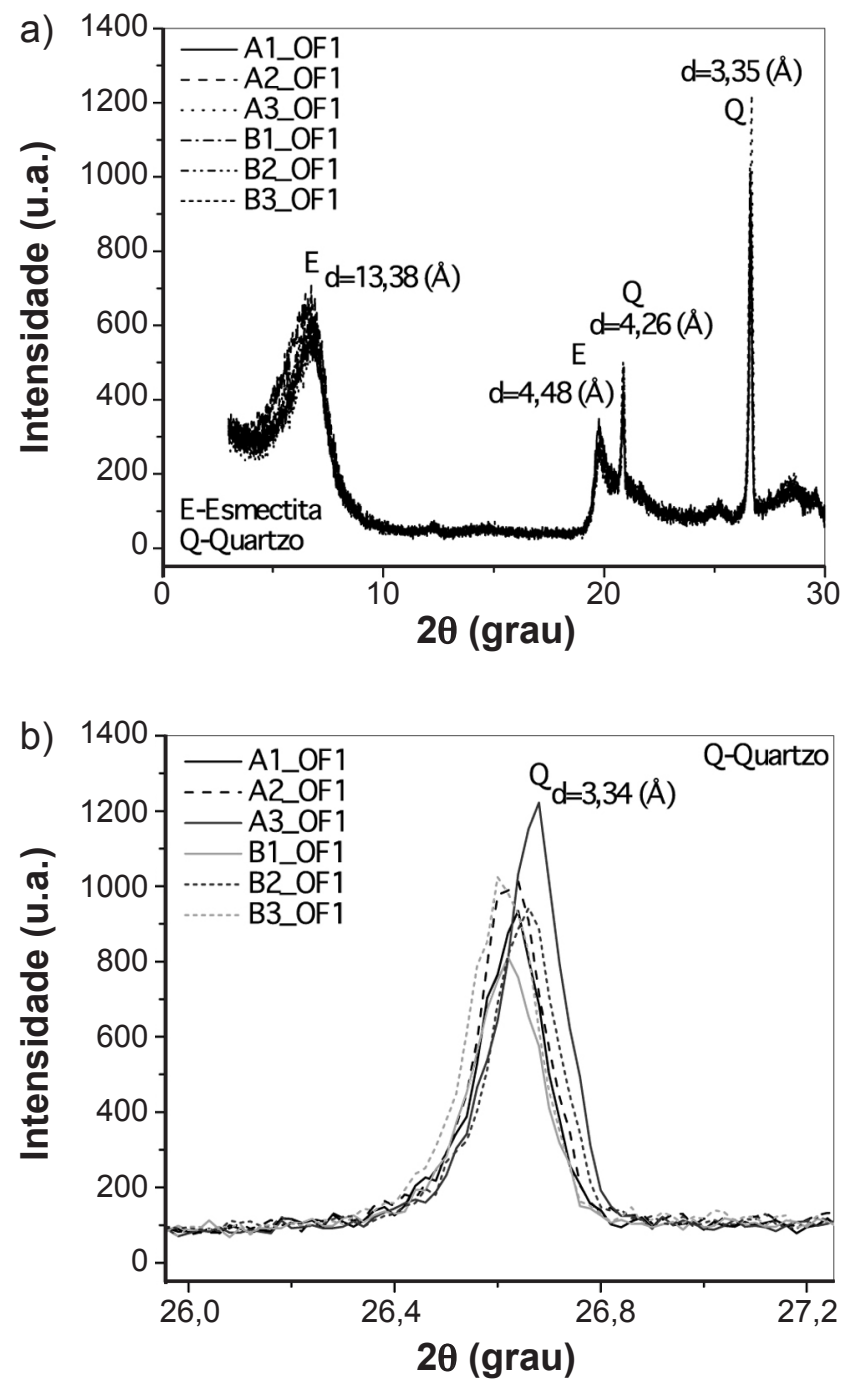

Figura 5: Difratogramas de raios $\mathrm{X}$ da argila Brasgel PA após hidrociclonagem.

[Figure 5: X-ray diffraction patterns of clay after hidrocyclonation Brasgel PA.]

se a presença do argilomineral esmectítico expandido caracterizado pelas distâncias interplanares de 13,38 Å e 4,48 Å. A presença de quartzo é caracterizada pelas distâncias de 4,26 ̊̊ e 3,34 Å. Pela Fig. 5b, observa-se apenas a presença do quartzo, caracterizado pela distância interplanar de 3,34 Å. É perceptível que ocorre maior redução do teor de quartzo nas amostras B1, B2 e A1, resultado que confirma os dados de analises granulométricas apresentados anteriormente.

Pelo difratograma da Fig. 6a, observa-se a presença do argilomineral esmectítico caracterizado pelas distâncias interplanares de $12,91 \AA$ e $4,45 \AA$. A presença de quartzo é caracterizada pelas distâncias de 3,34 Å e 4,25 Å. Pela Fig. 6(b), observa-se apenas a presença de quartzo pelas distâncias interplanares de 3,34 ̊ e 3,25 A. Observa-se novamente que as maiores intensidades do "underflow" são das amostras B1, B2 e A1, confirmando que estes conjuntos são os mais adequados para purificação da argila Brasgel PA. Uma análise conjunta dos resultados mostra que eficiência do processo de purificação através da hidrociclonagem 

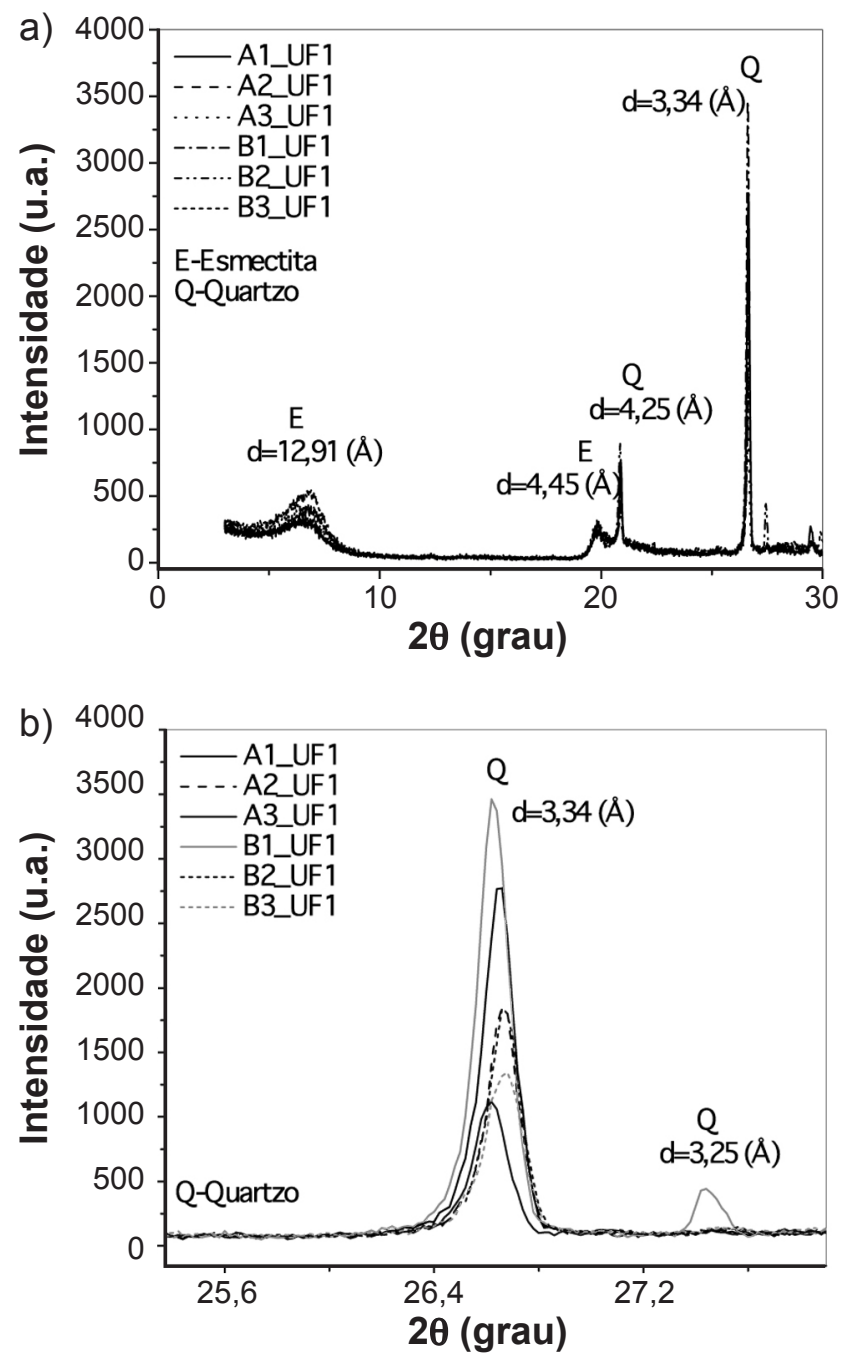

Figura 6: Difratogramas de raios $\mathrm{X}$ da argila Brasgel PA após hidrociclonagem.

[Figure 6: X-ray diffraction patterns of clay after hidrocyclonation Brasgel PA.]

pode ser facilmente observada por análise granulométrica e difração de raios $\mathrm{X}$ sendo os conjuntos mais eficientes o B1, B2 e A1.

As Figs. 7 e 8 mostram os resultados de difração de raios $\mathrm{X}$ da argila Chocolate após hidrociclonagem. Analisando o difratograma da Fig. 7a, observa-se a presença do argilomineral esmectítico, caracterizado pelas distâncias interplanares de $17,35 \AA$ e $4,48 \AA$. A presença de quartzo é caracterizada pelas distâncias de 4,24 ̊̊ e 3,34 ̊. Pela Fig. 7(b), observa-se apenas a presença de quartzo, caracterizado pela distância interplanar de 3,34 ̊. De acordo com o difratograma da Fig. 8a, observa-se a presença do argilomineral esmectítico caracterizado pelas distâncias interplanares de 14,94 Å e 4,47 Å. A presença de quartzo é caracterizada pelas distâncias de 4,24 ̊̊ e 3,34 Å. Pela Fig. 8(b), observa-se apenas a presença de quartzo pela distancia interplanar de 3,34 ̊.. Uma análise conjunta dos resultados mostra que não foi possível verificar através da difração de raios X a separação granulométrica da argila Chocolate
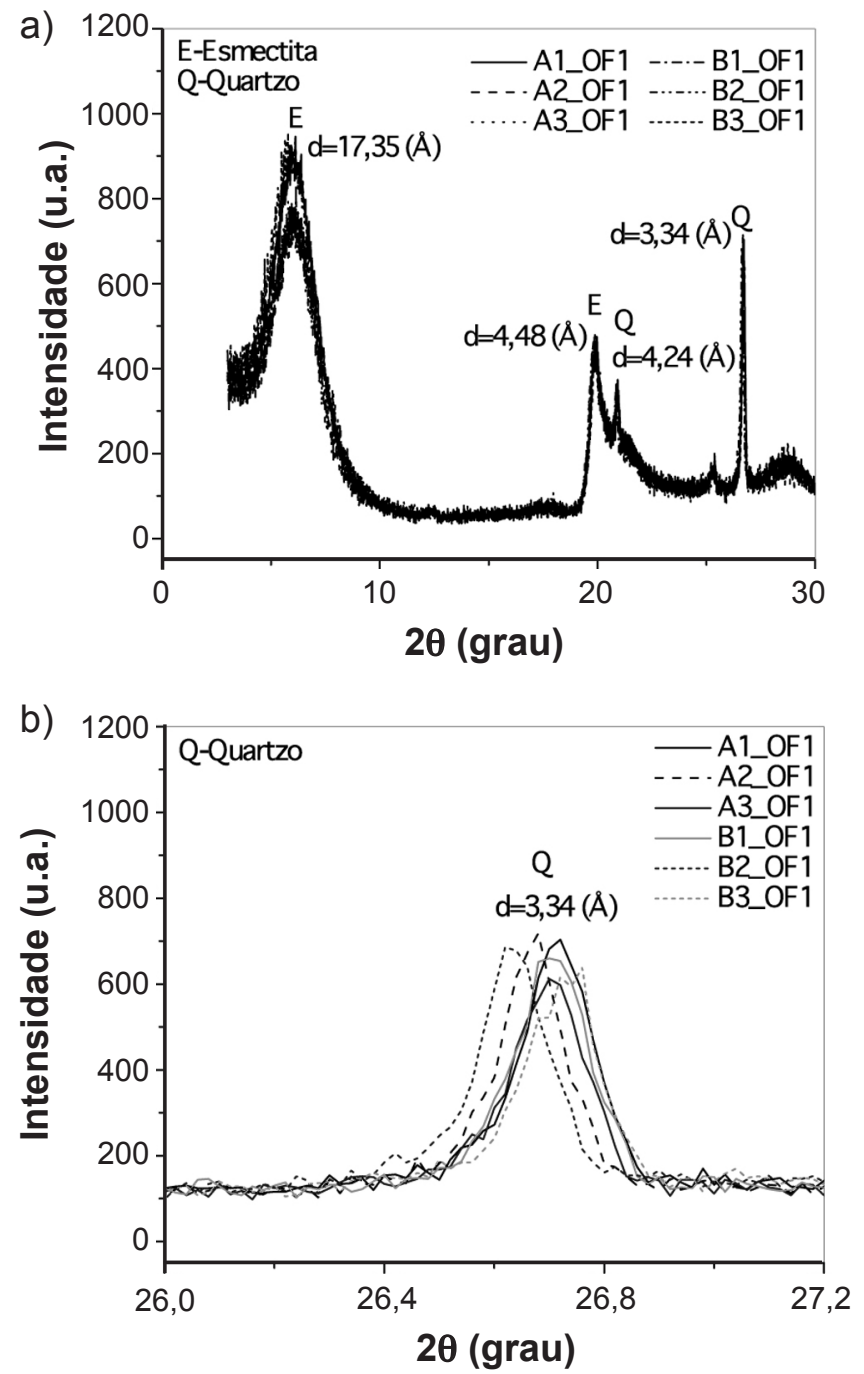

Figura 7: Difratogramas de raios $\mathrm{X}$ da argila Chocolate após hidrociclonagem.

[Figure 7: X-ray diffraction patterns of clay after hidrocyclonation Chocolate.]

através do processo de hidrociclonagem.

Através dos resultados das caracterizações das amostras purificadas, pode-se concluir que as melhores configurações para o hidrociclone são A1, A2, B1 e B2, sendo estas utilizadas para prosseguir o projeto com o processo de organofilização.

As Figs. 9 e 10 apresentam os difratogramas das argilas organofílicas obtidas a partir da argila Brasgel PA tratadas com $60 \%$ do tensoativo iônico Praepagen WB e do tensoativo não iônico Imidazolina Oléica Vegetal, respectivamente. Na Fig. 9a é mostrado o difratograma da argila organofílica obtida a partir da dispersão da argila Brasgel PA natural, ou seja, sem que tenha passado pelo processo de purificação. Observa-se a presença do argilomineral esmectítico caracterizado pela distância interplanar de 38,88 ̊̊. Na Fig. $9 \mathrm{~b}$ tem-se os difratogramas das argilas organofílicas obtidas a partir de dispersões da Brasgel PA purificadas. Em todas as amostras a distância original da Brasgel PA aumentou de cerca de $12 \AA$ para cerca de $37,40 \AA$. O aumento do pico 

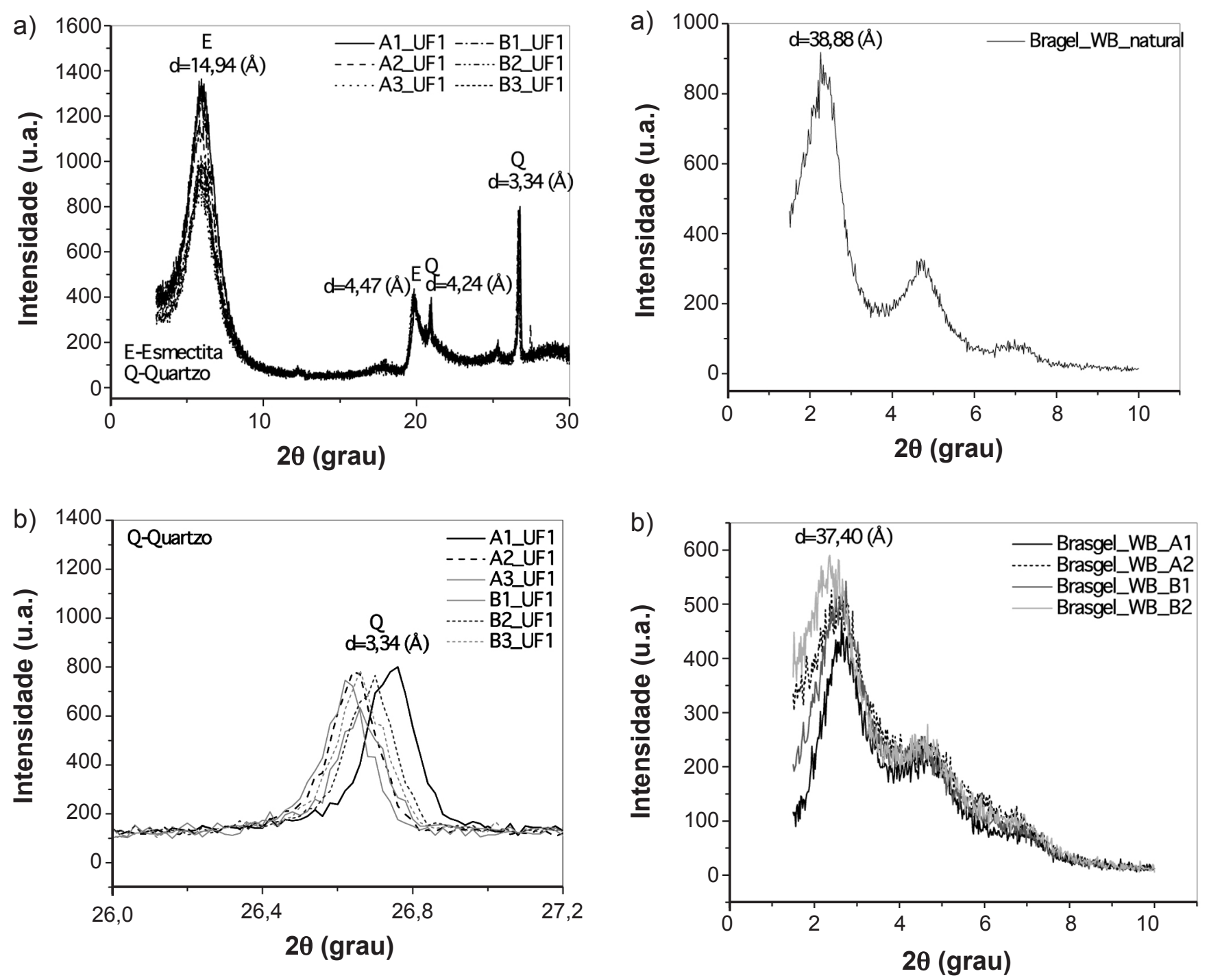

Figura 8: Difratogramas de raios $\mathrm{X}$ da argila Chocolate após hidrociclonagem.

[Figure 8: X-ray diffraction patterns of clay after hidrocyclonation Chocolate.]

característico do argilomineral esmectítico indica que houve intercalação do tensoativo iônico na fração argila.

$\mathrm{Na}$ Fig. 10a é mostrado o difratograma da argila organofílica obtida a partir da dispersão da argila Brasgel PA natural; observa-se a presença do argilomineral esmectítico expandido caracterizado pela distância interplanar de $45,73 \AA$ A. Na Fig. 10b tem-se os difratogramas das argilas organofílicas obtidas a partir de dispersões da Brasgel PA purificadas. Em todas as amostras a distância original da Brasgel PA aumentou de cerca de $12 \AA$ para cerca de $40,86 \AA$. O aumento do pico característico do argilomineral esmectítico indica que houve intercalação do tensoativo não iônico na fração argila.

As Figs. 11 e 12 apresentam os difratogramas das argilas organofílicas obtidas a partir da argila Chocolate sem defloculante tratadas com $60 \%$ do tensoativo iônico Praepagen WB e com o tensoativo não iônico Imidazolina Oléica Vegetal, respectivamente. Na Fig. 11a é mostrado

Figura 9: Difratogramas de raios $\mathrm{X}$ da argila Brasgel PA organofilizada com o tensoativo iônico Praepagen WB.

[Figure 9: X-ray diffraction patterns of clay Brasgel PA organofilized with the ionic surfactant Praepagen WB.]

o difratograma da argila organofílica obtida a partir da dispersão da argila Chocolate sem defloculante natural. Observa-se a presença do argilomineral esmectítico expandido caracterizado pela distância interplanar de $39,41 \AA$ A. Na Fig. 11b tem-se os difratogramas das argilas organofílicas obtidas a partir de dispersões da Chocolate sem defloculante purificadas. Em todas as amostras a distância original da argila Chocolate aumentou de cerca de $14 \AA$ para cerca de $33,44 \AA$. O aumento do pico característico do argilomineral esmectítico indica que houve intercalação do tensoativo iônico na fração argila.

Na Fig. 12a é mostrado o difratograma da argila organofílica obtida a partir da dispersão da argila Chocolate sem defloculante natural, observa-se a presença do argilomineral esmectítico expandido caracterizado pela distância interplanar de 36,18 Å. Na Fig. 12b observa-se os difratogramas das argilas organofílicas obtidas a partir de dispersões da Chocolate purificadas. Em todas as amostras a 

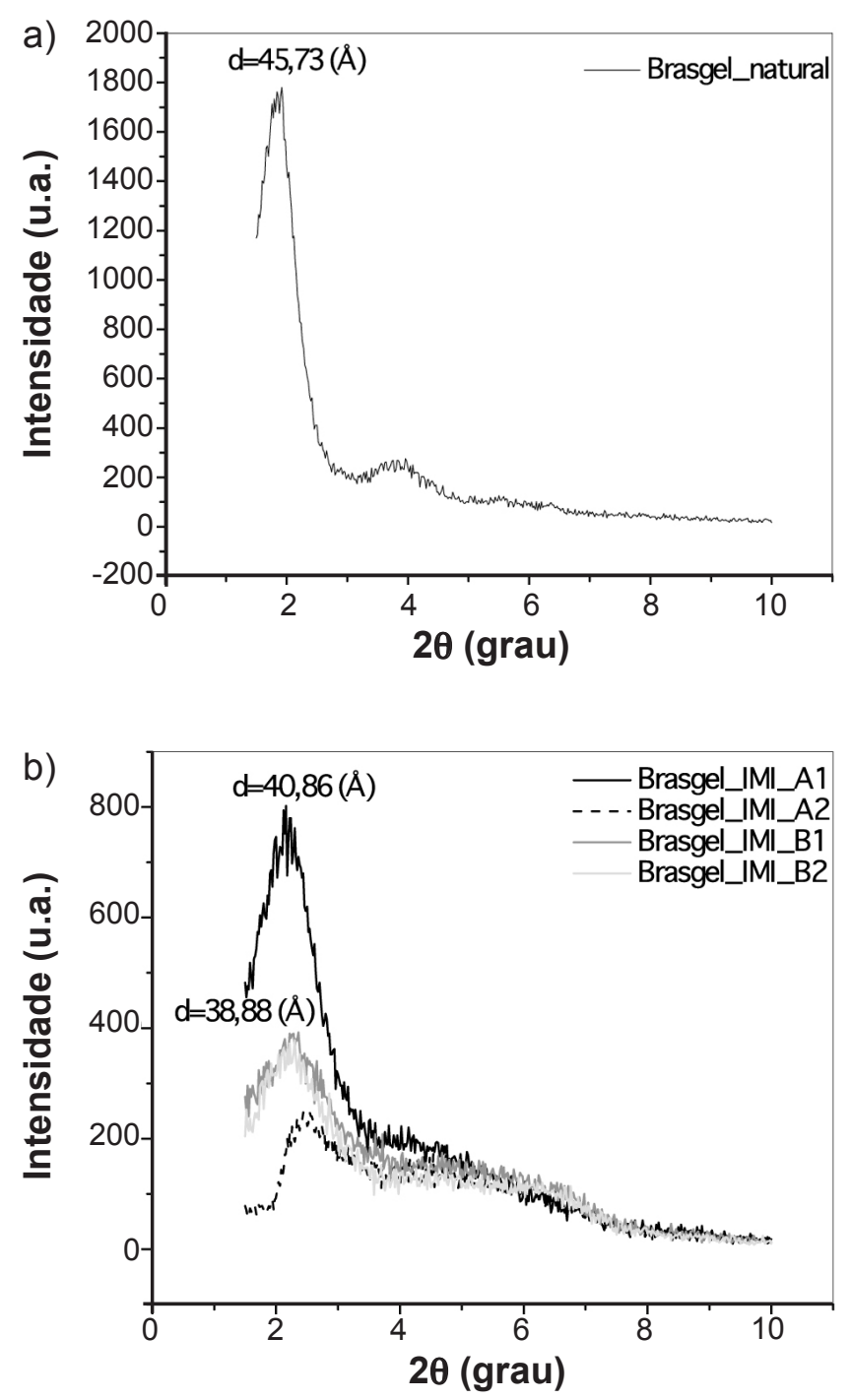

Figura 10: Difratogramas de raios $\mathrm{X}$ da argila Brasgel PA organofilizada com o tensoativo não iônico Imidazolina Oléica Vegetal.

[Figure 10:X-raydiffraction patterns of clayBrasgel PAorganofilized with the non ionic surfactant Oleic Vegetable Imidazoline.]

distância original da Chocolate aumentou de cerca de $14 \AA$ para cerca de 39,94 ̊. O aumento do pico característico do argilomineral esmectítico indica que houve intercalação do tensoativo não iônico na fração argila.

As Figs. 13 e 14 apresentam os difratogramas das argilas organofílicas obtidas a partir da argila Chocolate com defloculante tratadas com $60 \%$ do tensoativo iônico Praepagen WB e com o tensoativo não iônico Imidazolina Oléica Vegetal, respectivamente. Na Fig. 13a é mostrado o difratograma da argila organofílica obtida a partir da dispersão da argila Chocolate com defloculante natural. Observa-se o argilomineral esmectítico expandido caracterizado pela distância interplanar de 32,94 ̊. Na Fig. 13b tem-se os difratogramas das argilas organofílicas obtidas a partir de dispersões da Chocolate com defloculante purificadas. Em todas as amostras a distância original da Chocolate com

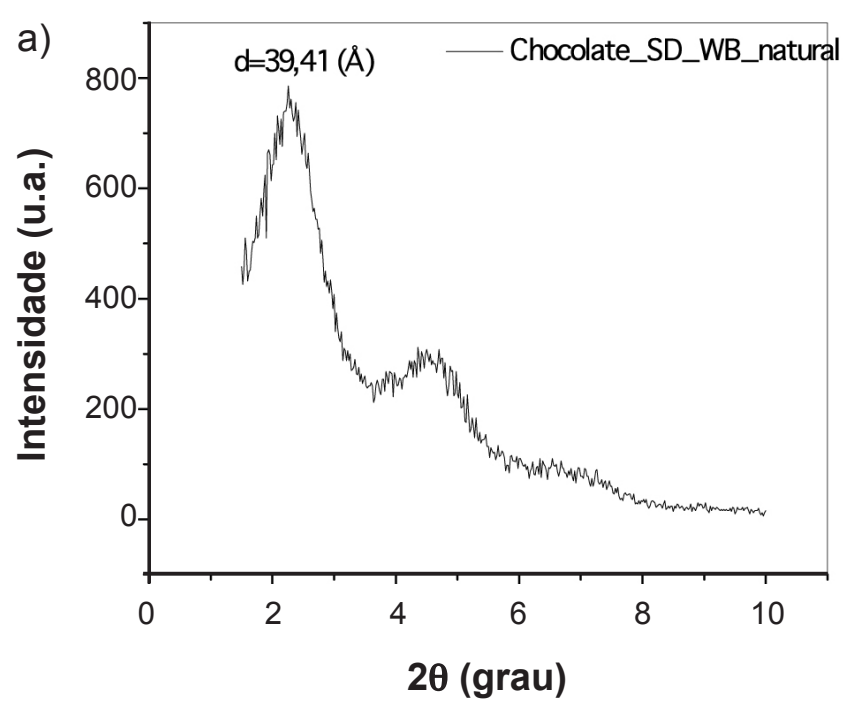

b)

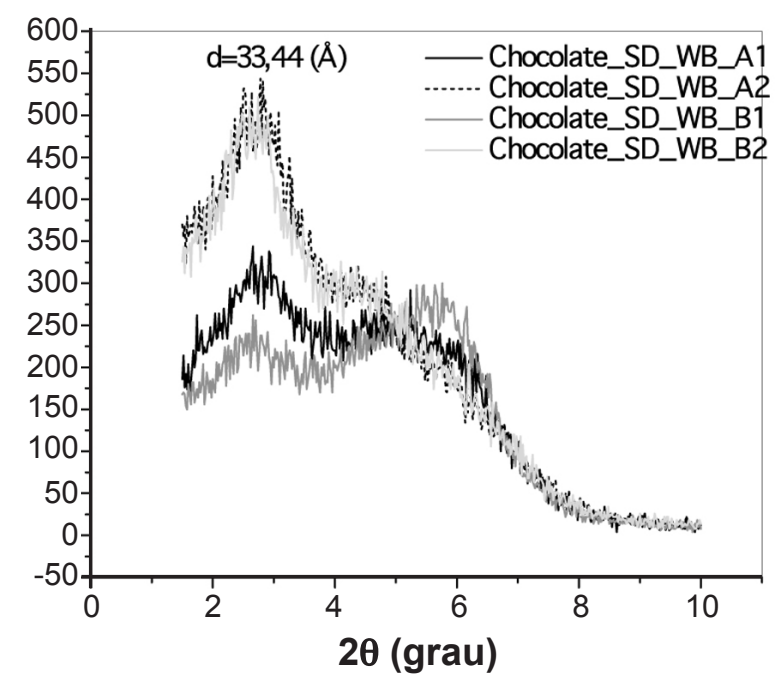

Figura 11: Difratogramas de raios $\mathrm{X}$ da argila Chocolate sem defloculante organofilizada com o tensoativo iônico Praepagen WB.

[Figure 11: X-ray diffraction patterns of Chocolate clay without deflocculant organofilized with Praepagen WB ionic surfactant.]

defloculante aumentou de cerca de $14 \AA$ A para cerca de $35,17 \AA$. O aumento do pico característico do argilomineral esmectítico indica que houve intercalação do tensoativo iônico na fração argila. Na Fig. 14a é mostrado o difratograma da argila organofílica obtida a partir da dispersão da argila Chocolate com defloculante natural, observa-se o argilomineral esmectítico expandido caracterizado pela distância interplanar de 47,20 A. Na Fig. 14b observa-se os difratogramas das argilas organofílicas obtidas a partir de dispersões da Chocolate com defloculante purificadas. Em todas as amostras a distância original da Chocolate com defloculante aumentou de cerca de $14 \AA$ para cerca de $46,21 \AA$ Å. O aumento do pico característico do argilomineral esmectítico indica que houve intercalação do tensoativo não iônico na fração argila.

Uma análise de todos os resultados mostra que a obtenção de argilas organofílicas foi adequada, obtendo-se 
a)
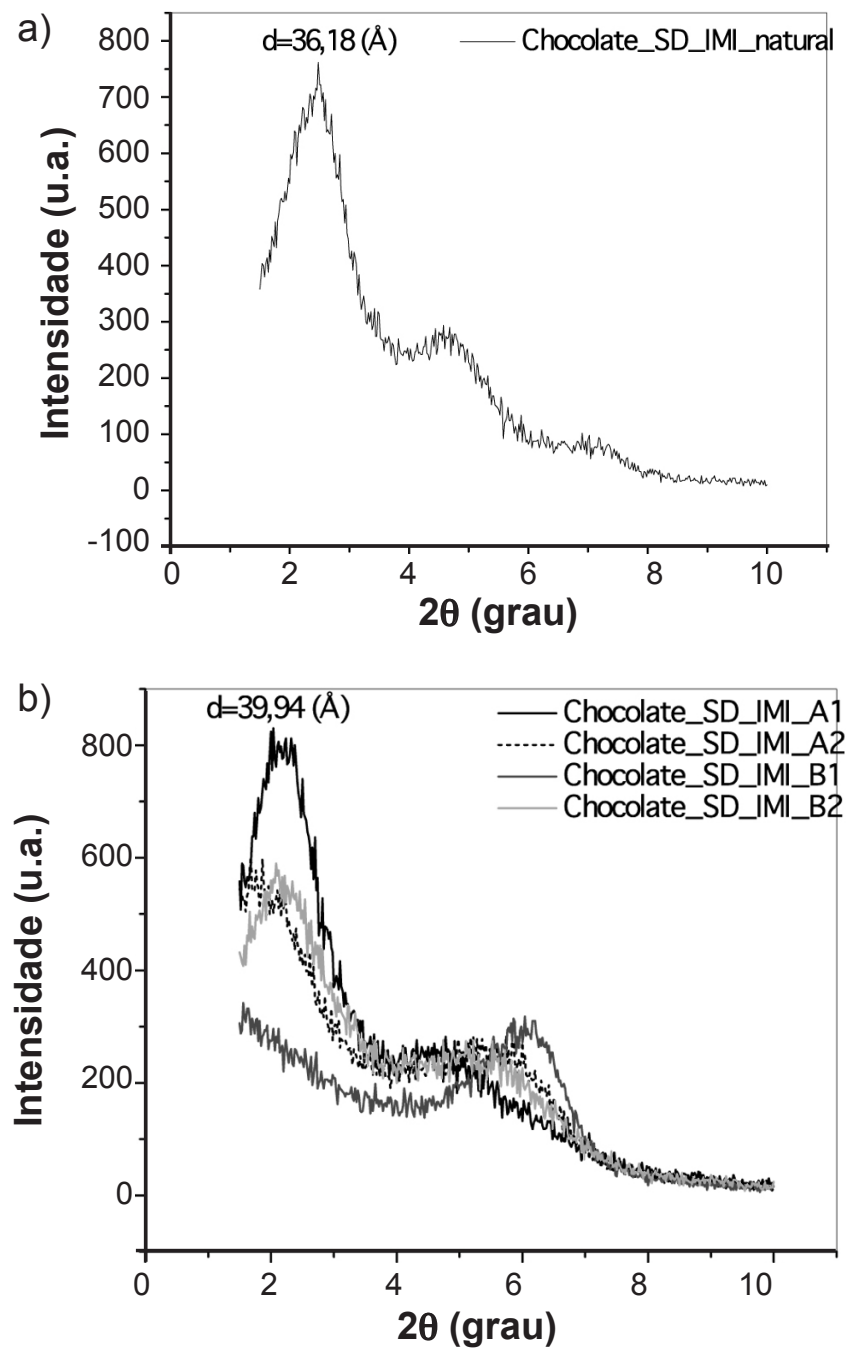

Figura 12: Difratogramas de raios $\mathrm{X}$ da argila Chocolate sem defloculante organofilizada com o tensoativo não iônico Imidazolina Oléica Vegetal.

[Figure 12: X-ray diffraction patterns of Chocolate clay without deflocculant organofilized with Oleic Vegetable Imidazoline non ionic surfactant.]

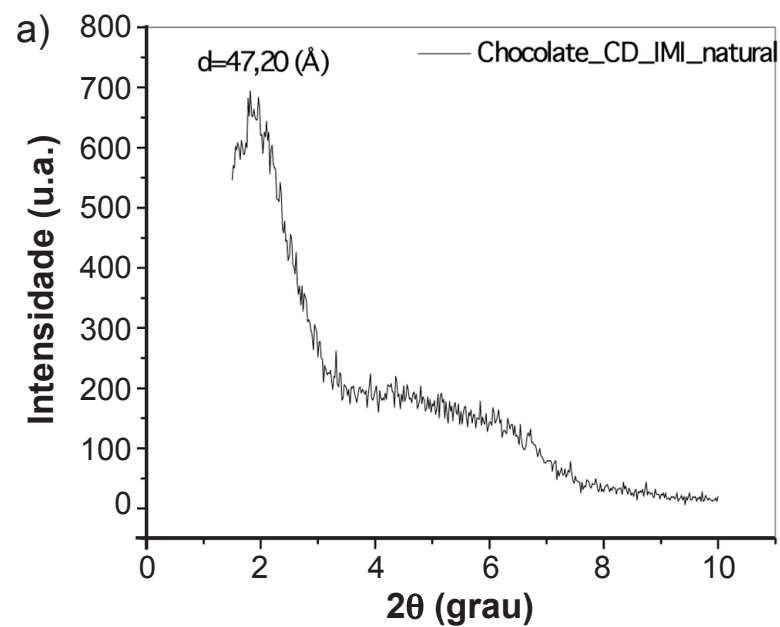

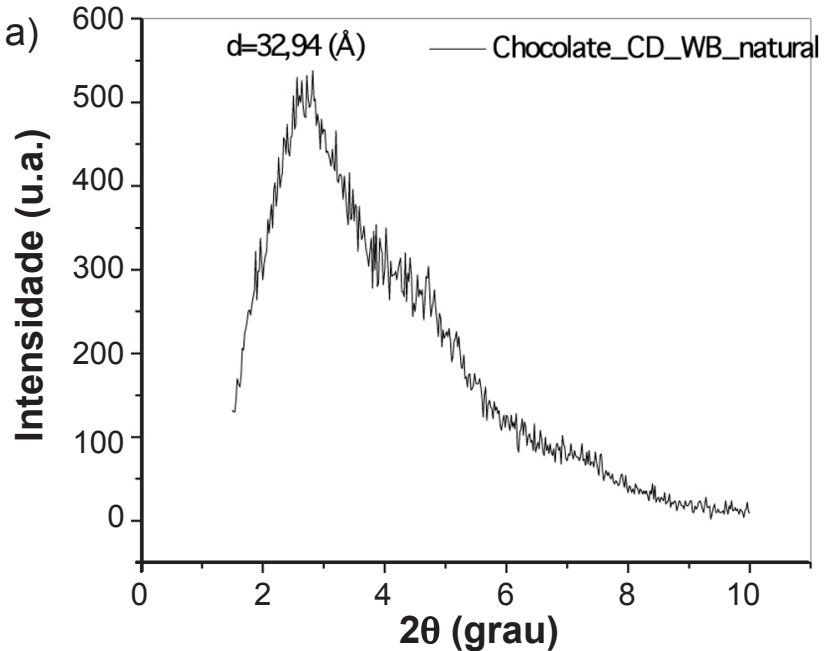

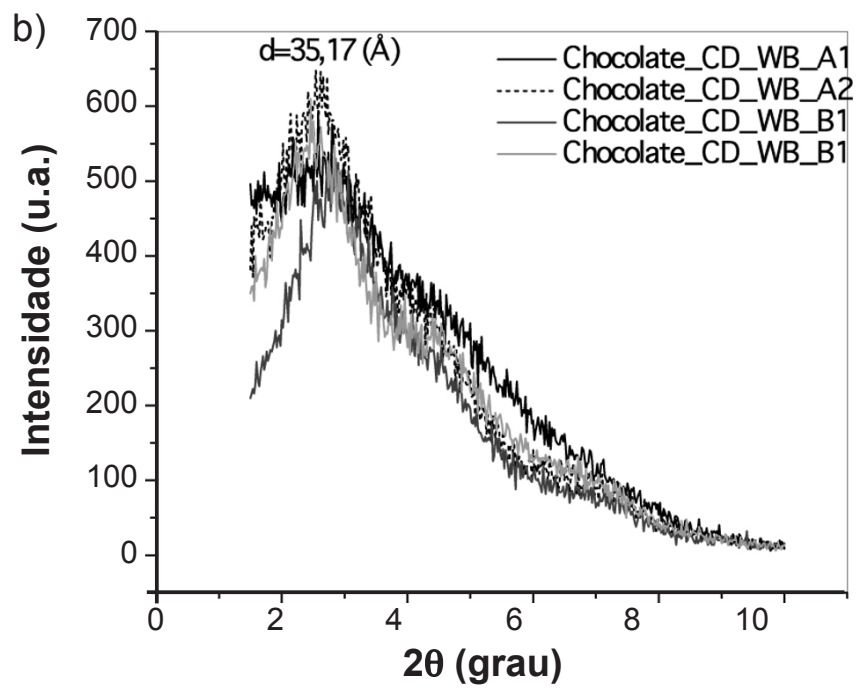

Figura 13: Difratogramas de raios $\mathrm{X}$ da argila Chocolate com defloculante organofilizada com o tensoativo iônico Praepagen WB.

[Figure 13: X-ray diffraction patterns of Chocolate clay with deflocculant organofilized with the ionic surfactant Praepagen WB.]

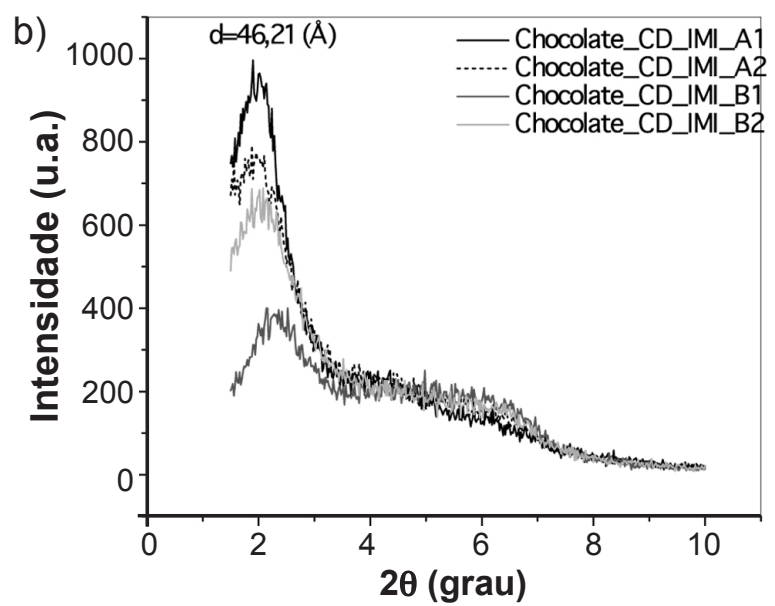

Figura 14: Difratogramas de raios X da argila Chocolate com defloculante organofilizada com o tensoativo não iônico Imidazolina Oléica Vegetal. [Figure 14:X-ray diffraction patterns of Chocolate clay with deflocculant organofilized with the non ionic surfactant Oleic Vegetable Imidazoline.] 
a intercalação das moléculas de ambos os tensoativos entre as lâminas do argilomineral, após apresentar distância basal superior a $30,0 \AA$.

Nas Tabelas X, XI e XII são apresentados os resultados estatísticos dos inchamentos de Foster das argilas organofílicas purificadas obtidas a partir da argila Brasgel PA, Chocolate sem defloculante e Chocolate com defloculante, respectivamente, tratadas com o tensoativo iônico Praepagen WB e com o não iônico Imidazolina Oléica Vegetal, no teor de $60 \%$, nos meios orgânicos parafina, éster e óleo diesel. Os resultados evidenciam que algumas amostras se apresentaram sem inchamento ou com baixo inchamento tanto com agitação quanto sem agitação, havendo, dessa forma, pouca afinidade química entre os tensoativos e a parafina. Para os meios dispersantes éster e óleo diesel, as amostras apresentaram baixo inchamento ou com alto inchamento, tanto com agitação quanto sem agitação, havendo uma melhor afinidade química entre os tensoativos destes meios orgânicos do que com a parafina.

Analisando de forma geral os dois conjuntos, verificou-se que o tensoativo Praepagen WB e Imidazolina Oléica Vegetal possuem melhor afinidade com o éster, posteriormente com o diesel e por ultimo com a parafina, como mostraram os resultados de inchamento de Foster. Além disso, verificase que o tensoativo Praepagen WB é melhor do que a Imidazolina Oléica Vegetal.

Na Tabela XIII e XIV, apresentam-se os resultados de viscosidade aparente e plástica das dispersões obtidas com suas respectivas configurações no hidrociclone e com os tensoativos Praepagen WB e Imidazolina Oléica Vegetal, respectivamente, para a argila Brasgel PA. Podese observar que apenas a Brasgel PA natural organofilizada com o tensoativo iônico Praepagen WB nos quatro teores normatizados, conduziu a resultados adequados frente a normatização da Petrobrás para o meio parafina. Para o meio orgânico éster todos foram satisfatório frente a normatização

Tabela X - Inchamento de Foster da argila organofílica Brasgel PA com Praepagen WB/ Imidazolina Oléica Vegetal.

[Table X - Foster's swelling of Brasgel PA organoclay with Praepagen WB / Oleic Vegetable Imidazoline.]

\begin{tabular}{ccccccc}
\hline \multirow{2}{*}{$\begin{array}{c}\text { Amostra } \\
\text { Brasgel }\end{array}$} & $\begin{array}{c}\text { Parafina } \\
\text { 24 h sem } \\
\text { agitação (mL) }\end{array}$ & $\begin{array}{c}24 \text { h com } \\
\text { agitação (mL) }\end{array}$ & $\begin{array}{c}24 \text { h sem } \\
\text { agitação (mL) }\end{array}$ & $\begin{array}{c}\text { Éster } \\
\text { agitação (mL) }\end{array}$ & $\begin{array}{c}\text { Óleo Diesel } \\
\text { agitação (mL) }\end{array}$ & $\begin{array}{c}24 \mathrm{~h} \text { com } \\
\text { agitação (mL) }\end{array}$ \\
\hline WB_natural & 3,5 & 4,5 & 9,0 & 10,0 & 12,0 & 17,0 \\
WB_A1 & 3,5 & 4,0 & 9,0 & 10,0 & 8,0 & 12,0 \\
WB_A2 & 2,5 & 2,5 & 6,0 & 7,0 & 4,0 & 5,0 \\
WB_B1 & 3,5 & 4,5 & 8,5 & 9,0 & 7,0 & 9,0 \\
WB_B2 & 3,0 & 3,0 & 7,0 & 8,0 & 4,0 & 6,0 \\
IMI_natural & 5,0 & 6,5 & 6,0 & 6,0 & 5,0 & 5,0 \\
IMI_A1 & 2,0 & 3,0 & 2,0 & 3,0 & 2,0 & 2,0 \\
IMI_A2 & 1,5 & 3,0 & 2,0 & 3,0 & 1,5 & 2,0 \\
IMI_B1 & 1,0 & 2,5 & 1,5 & 2,0 & 1,5 & 2,0 \\
IMI_B2 & 1,5 & 3,0 & 1,5 & 2,0 & 1,5 & 2,0 \\
\hline
\end{tabular}

Tabela XI - Inchamento de Foster da argila organofílica Chocolate sem defloculante Praepagen WB/ Imidazolina Oléica Vegetal.

[Table XI - Foster's swelling of Chocolate organoclay with deflocculant Praepagen WB / Oleic Vegetable Imidazoline.]

\begin{tabular}{|c|c|c|c|c|c|c|}
\hline \multirow{2}{*}{$\begin{array}{l}\text { Amostra } \\
\text { Chocolate }\end{array}$} & \multicolumn{2}{|c|}{ Parafina } & \multicolumn{2}{|c|}{ Éster } & \multicolumn{2}{|c|}{ Óleo Diesel } \\
\hline & $\begin{array}{c}24 \text { h sem } \\
\text { agitação }(\mathrm{mL})\end{array}$ & $\begin{array}{c}24 \text { h com } \\
\text { agitação (mL) }\end{array}$ & $\begin{array}{c}24 \text { h sem } \\
\text { agitação }(\mathrm{mL})\end{array}$ & $\begin{array}{c}24 \text { h com } \\
\text { agitação (mL) }\end{array}$ & $\begin{array}{c}24 \mathrm{~h} \text { sem } \\
\text { agitação (mL) }\end{array}$ & $\begin{array}{c}24 \text { h com } \\
\text { agitação }(\mathrm{mL})\end{array}$ \\
\hline SD_WB_natural & 3,5 & 3,5 & 10,0 & 12,0 & 10,0 & 15,0 \\
\hline SD_WB_A1 & 2,0 & 3,0 & 6,5 & 7,0 & 4,0 & 5,0 \\
\hline SD_WB_A2 & 3,0 & 4,0 & 9,0 & 9,0 & 5,0 & 6,0 \\
\hline SD_WB_B1 & 2,0 & 2,0 & 5,0 & 6,0 & 3,0 & 4,0 \\
\hline SD_WB_B2 & 3,0 & 3,0 & 8,0 & 8,0 & 5,0 & 7,0 \\
\hline SD_IMI_natural & 4,0 & 4,0 & 5,0 & 8,0 & 5,0 & 7,0 \\
\hline SD_IMI_A1 & 2,5 & 3,0 & 2,5 & 5,0 & 2,0 & 3,0 \\
\hline SD_IMI_A2 & 2,0 & 2,5 & 2,0 & 3,0 & 2,0 & 2,5 \\
\hline SD_IMI_B1 & 2,0 & 3,0 & 2,0 & 2,0 & 2,0 & 2,0 \\
\hline SD_IMI_B2 & 2,5 & 3,0 & 2,0 & 2,0 & 3,0 & 3,0 \\
\hline
\end{tabular}


da Petrobrás. Já para o óleo diesel foram obtidos resultados satisfatórios apenas nos teores de 2,4 g e 6,0 g apenas para a Brasgel PA natural organofilizada com o tensoativo iônico Praepagen WB [21].

No que se refere às amostras de argilas purificadas para o tensoativo iônico Praepagen WB, apenas a configuração A1, na quantidade referente a 13,2 g, apresentou resultados adequados frente a normatização da Petrobrás [21]. No que se refere aos resultados obtidos com o tensoativo Imidazolina Oléica Vegetal, nenhum dos resultados foi satisfatório frente a normatização da Petrobrás, exceto o éster nos teores de 2,4 g e 6,0 g [21].

Nas Tabelas XV, XVI, XVII e XVIII são apresentados os resultados de viscosidade aparente e plástica das dispersões

Tabela XII - Inchamento de Foster da argila organofílica Chocolate com defloculante - WB/ Imidazolina Oléica Vegetal.

[Table XII - Foster's swelling of Chocolate organoclay with Praepagen WB / Oleic Vegetable Imidazoline.]

\begin{tabular}{ccccccc}
\hline \multirow{2}{*}{$\begin{array}{c}\text { Amostra } \\
\text { Chocolate }\end{array}$} & $\begin{array}{c}\text { Parafina } \\
\text { 24 h sem } \\
\text { agitação (mL) }\end{array}$ & $\begin{array}{c}\text { 24 h com } \\
\text { agitação (mL) }\end{array}$ & $\begin{array}{c}\text { 24 h sem } \\
\text { agitação (mL) }\end{array}$ & $\begin{array}{c}\text { 24 h com } \\
\text { agitação (mL) }\end{array}$ & $\begin{array}{c}\text { 24 h sem } \\
\text { agitação (mL) }\end{array}$ & $\begin{array}{c}24 \mathrm{~h} \text { com } \\
\text { agitação (mL) }\end{array}$ \\
\hline CD_WB_natural & 3,0 & 3,0 & 8,0 & 9,0 & 5,0 & 7,0 \\
CD_WB_A1 & 1,5 & 2,0 & 6,0 & 6,0 & 3,0 & 5,0 \\
CD_WB_A2 & 2,5 & 2,5 & 9,0 & 10,0 & 5,0 & 7,0 \\
CD_WB_B1 & 3,0 & 3,0 & 11,0 & 11,0 & 5,0 & 8,0 \\
CD_WB_B2 & 2,0 & 2,5 & 7,0 & 7,0 & 4,0 & 5,0 \\
CD_IMI_natural & 2,0 & 2,0 & 3,0 & 3,5 & 3,0 & 3,0 \\
CD_IMI_A1 & 2,5 & 3,0 & 4,0 & 4,5 & 2,0 & 3,0 \\
CD_IMI_A2 & 2,5 & 2,5 & 3,0 & 4,0 & 2,5 & 2,5 \\
CD_IMI_B1 & 2,0 & 2,0 & 3,0 & 4,5 & 2,5 & 2,5 \\
CD_IMI_B2 & 1,5 & 1,5 & 3,0 & 4,0 & 2,0 & 2,0 \\
\hline
\end{tabular}

Tabela XIII - Viscosidades das argilas estudadas preparadas com o tensoativo Praepagen WB. [Table XIII - Viscosity of clays prepared with Praepagen WB surfactant.]

\begin{tabular}{|c|c|c|c|c|c|c|c|}
\hline \multirow[b]{2}{*}{$\begin{array}{c}\text { Amostra } \\
\text { Brasgel }\end{array}$} & \multirow[b]{2}{*}{$\begin{array}{l}\text { Quant. da } \\
\text { argila (g) }\end{array}$} & \multicolumn{2}{|c|}{ Parafina } & \multicolumn{2}{|c|}{ Éster } & \multicolumn{2}{|c|}{ Óleo Diesel } \\
\hline & & $\mathrm{VA}(\mathrm{cP})$ & $\begin{array}{l}\mathrm{VP} \\
(\mathrm{cP})\end{array}$ & $\mathrm{VA}(\mathrm{cP})$ & $\mathrm{VP}(\mathrm{cP})$ & $\mathrm{VA}(\mathrm{cP})$ & $\begin{array}{l}\mathrm{VP} \\
\text { (cP) }\end{array}$ \\
\hline \multirow{4}{*}{ WB_natural } & 2,4 & 6,0 & 5,0 & 14,5 & 11,0 & 8,3 & 7,5 \\
\hline & 6,0 & 10,0 & 7,0 & 23,5 & 16,0 & 8,5 & 7,0 \\
\hline & 9,6 & 13,0 & 9,0 & 30,0 & 15,0 & 9,3 & 7,0 \\
\hline & 13,2 & 24,5 & 10,0 & 36,5 & 21,0 & 12,0 & 8,0 \\
\hline \multirow{4}{*}{ WB_A1 } & 2,4 & 5,5 & 4,0 & 11,5 & 10,0 & 6,5 & 7,0 \\
\hline & 6,0 & 7,0 & 5,0 & 16,5 & 12,0 & 7,0 & 7,0 \\
\hline & 9,6 & 9,0 & 6,0 & 21,5 & 15,0 & 9,0 & 7,0 \\
\hline & 13,2 & 17,0 & 8,0 & 22,5 & 15,0 & 12,0 & 8,0 \\
\hline \multirow{4}{*}{ WB_A2 } & 2,4 & 4,0 & 4,0 & 15,3 & 13,0 & 6,3 & 5,5 \\
\hline & 6,0 & 5,8 & 4,5 & 16,3 & 13,5 & 7,3 & 6,5 \\
\hline & 9,6 & 8,8 & 6,0 & 18,8 & 13,0 & 8,5 & 7,5 \\
\hline & 13,2 & 9,3 & 5,0 & 21,0 & 15,0 & 10,8 & 7,5 \\
\hline \multirow{4}{*}{ WB_B1 } & 2,4 & 4,0 & 3,0 & 12,5 & 11,0 & 6,5 & 7,0 \\
\hline & 6,0 & 5,5 & 4,0 & 15,5 & 11,0 & 6,8 & 6,5 \\
\hline & 9,6 & 8,0 & 6,0 & 38,8 & 27,5 & 8,5 & 7,0 \\
\hline & 13,2 & 11,0 & 6,0 & 62,0 & 50,0 & 11,0 & 8,0 \\
\hline \multirow{4}{*}{ WB_B2 } & 2,4 & 4,0 & 4,0 & 11,5 & 10,5 & 5,5 & 5,0 \\
\hline & 6,0 & 5,5 & 4,0 & 15,0 & 12,0 & 6,3 & 5,5 \\
\hline & 9,6 & 8,0 & 5,0 & 20,0 & 15,0 & 7,5 & 6,5 \\
\hline & 13,2 & 11,0 & 6,0 & 28,0 & 20,0 & 11,0 & 8,0 \\
\hline
\end{tabular}


Tabela XIV - Viscosidades das argilas estudadas preparadas com Imidazolina Oléica Vegetal. [Table XIV - Viscosity of clays prepared with Oleic Vegetable Imidazoline surfactant.]

\begin{tabular}{|c|c|c|c|c|c|c|c|}
\hline \multirow[b]{2}{*}{$\begin{array}{c}\text { Amostra } \\
\text { Brasgel }\end{array}$} & \multirow[b]{2}{*}{$\begin{array}{l}\text { Quant. da } \\
\text { argila (g) }\end{array}$} & \multicolumn{2}{|c|}{ Parafina } & \multicolumn{2}{|c|}{ Éster } & \multicolumn{2}{|c|}{ Óleo Diesel } \\
\hline & & $\begin{array}{l}\text { VA } \\
(\mathrm{cP})\end{array}$ & $\begin{array}{l}\mathrm{VP} \\
(\mathrm{cP})\end{array}$ & $\begin{array}{l}\mathrm{VA} \\
(\mathrm{cP})\end{array}$ & $\begin{array}{l}\text { VP } \\
(\mathrm{cP})\end{array}$ & $\begin{array}{l}\mathrm{VA} \\
(\mathrm{cP})\end{array}$ & $\begin{array}{l}\text { VP } \\
(\mathrm{cP})\end{array}$ \\
\hline \multirow{4}{*}{ IMI_natural } & 2,4 & 3,5 & 3,0 & 8,5 & 8,0 & 5,5 & 6,0 \\
\hline & 6,0 & 4,5 & 3,0 & 8,5 & 7,5 & 7,0 & 6,0 \\
\hline & 9,6 & 6,0 & 5,0 & 11,3 & 10,5 & 7,5 & 7,0 \\
\hline & 13,2 & 7,5 & 6,0 & 11,3 & 9,5 & 9,5 & 8,0 \\
\hline \multirow{4}{*}{ IMI_A1 } & 2,4 & 3,8 & 4,5 & 8,5 & 8,0 & 5,5 & 6,0 \\
\hline & 6,0 & 4,0 & 4,0 & 8,8 & 8,0 & 6,0 & 6,0 \\
\hline & 9,6 & 5,0 & 4,0 & 11,5 & 10,5 & 6,5 & 6,0 \\
\hline & 13,2 & 6,5 & 5,0 & 12,8 & 10,5 & 7,0 & 6,0 \\
\hline \multirow{4}{*}{ IMI_A2 } & 2,4 & 4,0 & 5,0 & 8,3 & 8,5 & 5,5 & 5,5 \\
\hline & 6,0 & 4,5 & 4,0 & 8,5 & 9,0 & 6,0 & 6,0 \\
\hline & 9,6 & 5,0 & 5,0 & 8,8 & 8,5 & 6,5 & 6,0 \\
\hline & 13,2 & 5,5 & 5,0 & 11,0 & 11,0 & 7,5 & 7,0 \\
\hline \multirow{4}{*}{ IMI_B1 } & 2,4 & 4,0 & 4,0 & 8,3 & 8,5 & 5,0 & 5,5 \\
\hline & 6,0 & 5,5 & 4,0 & 10,0 & 10,0 & 5,8 & 6,0 \\
\hline & 9,6 & 8,0 & 5,0 & 10,3 & 10,0 & 6,0 & 6,0 \\
\hline & 13,2 & 11,0 & 6,0 & 10,5 & 10,5 & 6,5 & 6,5 \\
\hline \multirow{4}{*}{ IMI_B2 } & 2,4 & 4,0 & 5,0 & 7,5 & 8,0 & 5,3 & 5,0 \\
\hline & 6,0 & 4,0 & 4,5 & 8,0 & 8,0 & 6,0 & 6,0 \\
\hline & 9,6 & 4,0 & 4,0 & 8,5 & 8,0 & 6,5 & 6,0 \\
\hline & 13,2 & 4,5 & 4,0 & 10,0 & 9,5 & 8,0 & 8,0 \\
\hline
\end{tabular}

Tabela XV - Viscosidades das argilas estudadas preparadas com o tensoativo Praepagen WB. [Table XV - Viscosity of clays prepared with Praepagen WB surfactant.]

\begin{tabular}{cccccccc}
\hline & & \multicolumn{2}{c}{ Parafina } & \multicolumn{2}{c}{ Éster } & \multicolumn{2}{c}{ Óleo Diesel } \\
\cline { 3 - 7 } Amostra & Quant. da & VA & VP & VA & VP & VA & VP \\
& argila $(\mathrm{g})$ & $(\mathrm{cP})$ & $(\mathrm{cP})$ & $(\mathrm{cP})$ & $(\mathrm{cP})$ & $(\mathrm{cP})$ & $(\mathrm{cP})$ \\
\hline \multirow{2}{*}{ CH_SD_WB_natural } & 2,4 & 7,0 & 6,0 & 8,5 & 7,0 & 9,8 & 11,5 \\
& 6,0 & 8,5 & 6,5 & 16,3 & 11,5 & 9,0 & 8,0 \\
& 9,6 & 8,3 & 5,5 & 24,5 & 18,0 & 10,8 & 7,5 \\
& 13,2 & 8,5 & 5,5 & 32,0 & 20,0 & 15,8 & 11,0 \\
CH_SD_WB_A1 & 2,4 & 7,0 & 6,0 & 9,0 & 8,0 & 6,5 & 6,0 \\
& 6,0 & 9,0 & 6,5 & 11,5 & 9,0 & 8,0 & 8,0 \\
& 9,6 & 9,5 & 6,0 & 12,0 & 8,0 & 8,5 & 8,0 \\
& 13,2 & 10,0 & 6,0 & 18,5 & 12,0 & 8,0 & 7,5 \\
CH_SD_WB_A2 & 2,4 & 7,0 & 5,5 & 10,0 & 9,0 & 7,0 & 7,0 \\
& 6,0 & 9,5 & 6,0 & 12,0 & 9,0 & 8,3 & 8,0 \\
& 9,6 & 9,0 & 6,0 & 16,5 & 12,0 & 9,0 & 8,0 \\
& 13,2 & 9,0 & 6,0 & 21,0 & 17,0 & 10,8 & 8,5 \\
& 2,4 & 5,3 & 5,0 & 8,0 & 8,0 & 6,8 & 6,5 \\
& 6,0 & 7,0 & 6,0 & 8,0 & 7,5 & 7,5 & 7,0 \\
CH_SD_WB_B1 & 9,6 & 10,5 & 12,0 & 10,5 & 9,0 & 8,0 & 8,0 \\
& 13,2 & 9,5 & 5,0 & 12,5 & 9,0 & 8,8 & 8,5 \\
& 2,4 & 7,3 & 5,5 & 7,5 & 6,5 & 7,5 & 8,0 \\
& 6,0 & 9,0 & 5,5 & 13,0 & 10,0 & 8,0 & 8,0 \\
& 9,6 & 7,5 & 5,0 & 16,0 & 10,0 & 9,0 & 8,0 \\
& 13,2 & 8,0 & 5,0 & 17,5 & 10,0 & 10,0 & 8,0 \\
\hline & & & & & & &
\end{tabular}


Tabela XVI - Viscosidades das argilas estudadas preparadas com Imidazolina Oléica Vegetal. [Table XVI - Viscosity of clays prepared with Oleic Vegetable Imidazoline surfactant.]

\begin{tabular}{|c|c|c|c|c|c|c|c|}
\hline \multirow[b]{2}{*}{ Amostra } & \multirow[b]{2}{*}{$\begin{array}{l}\text { Quant. da } \\
\text { argila (g) }\end{array}$} & \multicolumn{2}{|c|}{ Parafina } & \multicolumn{2}{|c|}{ Éster } & \multicolumn{2}{|c|}{ Óleo Diesel } \\
\hline & & $\mathrm{VA}(\mathrm{cP})$ & $\begin{array}{l}\mathrm{VP} \\
(\mathrm{cP})\end{array}$ & $\begin{array}{l}\mathrm{VA} \\
(\mathrm{cP})\end{array}$ & $\begin{array}{l}\mathrm{VP} \\
(\mathrm{cP})\end{array}$ & $\begin{array}{l}\mathrm{VA} \\
(\mathrm{cP})\end{array}$ & $\begin{array}{l}\mathrm{VP} \\
(\mathrm{cP})\end{array}$ \\
\hline \multirow{4}{*}{ CH_SD_IMI_natural } & 2,4 & 3,8 & 3,5 & 5,0 & 5,0 & 5,5 & 5,0 \\
\hline & 6,0 & 4,0 & 3,5 & 6,0 & 5,5 & 6,0 & 6,0 \\
\hline & 9,6 & 4,5 & 4,0 & 6,5 & 5,5 & 7,0 & 7,0 \\
\hline & 13,2 & 5,5 & 4,0 & 7,3 & 6,0 & 7,5 & 7,0 \\
\hline \multirow{4}{*}{ CH_SD_IMI_A1 } & 2,4 & 4,0 & 4,5 & 4,5 & 4,5 & 5,0 & 6,0 \\
\hline & 6,0 & 4,3 & 4,5 & 5,5 & 5,0 & 6,0 & 6,0 \\
\hline & 9,6 & 4,8 & 4,0 & 9,5 & 9,5 & 6,8 & 6,5 \\
\hline & 13,2 & 6,5 & 6,0 & 9,5 & 9,0 & 7,3 & 7,0 \\
\hline \multirow{4}{*}{ CH_SD_IMI_A2 } & 2,4 & 4,0 & 5,0 & 4,8 & 5,0 & 5,5 & 7,0 \\
\hline & 6,0 & 4,8 & 5,0 & 5,5 & 5,5 & 6,0 & 6,0 \\
\hline & 9,6 & 4,5 & 4,5 & 9,3 & 9,5 & 6,5 & 6,0 \\
\hline & 13,2 & 4,8 & 4,5 & 9,5 & 9,0 & 6,8 & 6,5 \\
\hline \multirow{4}{*}{ CH_SD_IMI_B1 } & 2,4 & 4,0 & 6,0 & 5,0 & 5,5 & 5,0 & 6,0 \\
\hline & 6,0 & 3,8 & 5,0 & 6,0 & 6,5 & 5,5 & 6,0 \\
\hline & 9,6 & 4,3 & 4,5 & 8,5 & 8,5 & 6,0 & 6,0 \\
\hline & 13,2 & 5,0 & 5,0 & 9,3 & 9,0 & 6,0 & 6,0 \\
\hline \multirow{4}{*}{ CH_SD_IMI_B2 } & 2,4 & 4,0 & 5,0 & 4,8 & 5,5 & 5,5 & 6,0 \\
\hline & 6,0 & 4,5 & 4,5 & 5,5 & 5,0 & 6,5 & 7,0 \\
\hline & 9,6 & 5,3 & 5,0 & 8,5 & 8,5 & 7,0 & 6,5 \\
\hline & 13,2 & 7,0 & 7,0 & 9,0 & 8,5 & 7,5 & 7,0 \\
\hline
\end{tabular}

Tabela XVII - Viscosidades das argilas estudadas preparadas com o tensoativo Praepagen WB. [Table XVII - Viscosity of clays prepared with Praepagen WB surfactant.]

\begin{tabular}{|c|c|c|c|c|c|c|c|}
\hline \multirow[b]{2}{*}{ Amostra } & \multirow[b]{2}{*}{$\begin{array}{l}\text { Quant. da } \\
\text { argila (g) }\end{array}$} & \multicolumn{2}{|c|}{ Parafina } & \multicolumn{2}{|c|}{ Éster } & \multicolumn{2}{|c|}{ Óleo Diesel } \\
\hline & & $\begin{array}{l}\mathrm{VA} \\
(\mathrm{cP})\end{array}$ & $\begin{array}{l}\mathrm{VP} \\
(\mathrm{cP})\end{array}$ & $\begin{array}{l}\mathrm{VA} \\
(\mathrm{cP})\end{array}$ & $\begin{array}{l}\mathrm{VP} \\
(\mathrm{cP})\end{array}$ & $\begin{array}{l}\mathrm{VA} \\
(\mathrm{cP})\end{array}$ & $\begin{array}{l}\mathrm{VP} \\
(\mathrm{cP})\end{array}$ \\
\hline \multirow{4}{*}{ CH_CD_WB_natural } & 2,4 & 4,0 & 3,5 & 7,8 & 8,0 & 8,0 & 8,5 \\
\hline & 6,0 & 5,5 & 5,0 & 10,5 & 9,0 & 7,5 & 7,0 \\
\hline & 9,6 & 6,3 & 4,0 & 17,0 & 12,0 & 8,3 & 7,5 \\
\hline & 13,2 & 7,0 & 5,0 & 20,8 & 13,5 & 11,0 & 9,0 \\
\hline \multirow{4}{*}{ CH_CD_WB_A1 } & 2,4 & 6,3 & 5,5 & 8,0 & 7,0 & 6,0 & 5,5 \\
\hline & 6,0 & 5,5 & 2,0 & 12,0 & 10,0 & 7,3 & 7,0 \\
\hline & 9,6 & 6,5 & 5,0 & 16,3 & 11,0 & 8,0 & 8,0 \\
\hline & 13,2 & 7,0 & 5,5 & 19,0 & 12,0 & 9,5 & 9,0 \\
\hline \multirow{4}{*}{ CH_CD_WB_A2 } & 2,4 & 4,3 & 4,0 & 9,5 & 10,5 & 9,0 & 10,0 \\
\hline & 6,0 & 5,5 & 4,0 & 12,3 & 9,5 & 7,5 & 7,5 \\
\hline & 9,6 & 7,5 & 5,5 & 16,3 & 13,5 & 8,8 & 7,5 \\
\hline & 13,2 & 7,8 & 5,0 & 19,0 & 9,0 & 13,0 & 10,0 \\
\hline \multirow{4}{*}{ CH_CD_WB_B1 } & 2,4 & 5,0 & 4,0 & 9,0 & 9,0 & 9,0 & 10,0 \\
\hline & 6,0 & 6,0 & 4,5 & 12,8 & 9,5 & 7,5 & 8,0 \\
\hline & 9,6 & 7,0 & 5,0 & 19,5 & 12,0 & 8,5 & 8,0 \\
\hline & 13,2 & 8,0 & 5,0 & 28,0 & 17,0 & 11,5 & 8,5 \\
\hline \multirow{4}{*}{ CH_CD_WB_B2 } & 2,4 & 5,5 & 5,0 & 8,5 & 9,5 & 6,8 & 6,5 \\
\hline & 6,0 & 7,0 & 5,0 & 11,5 & 8,0 & 7,5 & 7,5 \\
\hline & 9,6 & 7,0 & 5,0 & 14,0 & 9,5 & 8,3 & 7,0 \\
\hline & 13,2 & 7,5 & 5,0 & 18,8 & 12,0 & 10,8 & 8,5 \\
\hline
\end{tabular}


Tabela XVIII - Viscosidades das argilas estudadas preparadas com Imidazolina Oléica Vegetal. [Table XVIII - Viscosity of clays prepared with Oleic Vegetable Imidazoline surfactant.]

\begin{tabular}{|c|c|c|c|c|c|c|c|}
\hline \multirow[b]{2}{*}{ Amostra } & \multirow[b]{2}{*}{$\begin{array}{l}\text { Quant. da } \\
\text { argila (g) }\end{array}$} & \multicolumn{2}{|c|}{ Parafina } & \multicolumn{2}{|c|}{ Éster } & \multicolumn{2}{|c|}{ Óleo Diesel } \\
\hline & & $\mathrm{VA}(\mathrm{cP})$ & $\begin{array}{l}\mathrm{VP} \\
(\mathrm{cP})\end{array}$ & $\begin{array}{l}\mathrm{VA} \\
(\mathrm{cP})\end{array}$ & $\begin{array}{l}\mathrm{VP} \\
(\mathrm{cP})\end{array}$ & $\begin{array}{l}\mathrm{VA} \\
(\mathrm{cP})\end{array}$ & $\begin{array}{l}\text { VP } \\
(\mathrm{cP})\end{array}$ \\
\hline \multirow{4}{*}{ CH_CD_IMI_natural } & 2,4 & 4,0 & 4,5 & 16,8 & 16,5 & 5,0 & 5,0 \\
\hline & 6,0 & 4,5 & 4,5 & 18,5 & 18,0 & 6,0 & 6,0 \\
\hline & 9,6 & 4,5 & 4,5 & 22,5 & 16,0 & 6,5 & 6,5 \\
\hline & 13,2 & 5,0 & 5,0 & 25,0 & 24,0 & 7,0 & 6,5 \\
\hline \multirow{4}{*}{ CH_CD_IMI_A1 } & 2,4 & 3,8 & 4,0 & 9,3 & 9,0 & 6,0 & 6,5 \\
\hline & 6,0 & 3,8 & 3,5 & 9,3 & 9,0 & 7,0 & 7,0 \\
\hline & 9,6 & 4,0 & 3,5 & 11,0 & 11,0 & 7,5 & 7,5 \\
\hline & 13,2 & 4,3 & 3,5 & 11,0 & 11,0 & 7,8 & 7,5 \\
\hline \multirow{4}{*}{ CH_CD_IMI_A2 } & 2,4 & 4,0 & 4,0 & 9,8 & 9,5 & 6,5 & 7,0 \\
\hline & 6,0 & 3,8 & 4,5 & 8,8 & 9,0 & 4,3 & 4,5 \\
\hline & 9,6 & 4,3 & 4,0 & 10,0 & 9,5 & 7,0 & 6,5 \\
\hline & 13,2 & 5,0 & 5,0 & 10,5 & 10,5 & 7,5 & 7,0 \\
\hline \multirow{4}{*}{ CH_CD_IMI_B1 } & 2,4 & 4,0 & 4,5 & 8,8 & 8,5 & 6,0 & 7,0 \\
\hline & 6,0 & 4,3 & 4,5 & 9,0 & 9,0 & 6,3 & 6,5 \\
\hline & 9,6 & 4,0 & 4,0 & 8,5 & 8,5 & 6,8 & 6,5 \\
\hline & 13,2 & 4,5 & 4,5 & 10,0 & 10,0 & 7,3 & 7,0 \\
\hline \multirow{4}{*}{ CH_CD_IMI_B2 } & 2,4 & 4,0 & 4,5 & 5,3 & 6,5 & 5,5 & 6,5 \\
\hline & 6,0 & 4,3 & 4,5 & 5,5 & 5,5 & 6,5 & 7,0 \\
\hline & 9,6 & 4,5 & 6,0 & 6,5 & 6,5 & 6,8 & 6,5 \\
\hline & 13,2 & 5,0 & 5,0 & 6,8 & 6,5 & 7,0 & 7,0 \\
\hline
\end{tabular}

obtidas com suas respectivas configurações no hidrociclone e com os tensoativos Praepagen WB e Imidazolina Oléica Vegetal, para a argila Chocolate sem defloculante e Chocolate com defloculante.

Pode-se observar que para o meio orgânico éster todos os resultados foram satisfatório frente a normatização da Petrobrás para o tensoativo iônico Praepagen WB [21]. No que se refere aos resultados obtidos com o tensoativo Imidazolina Oléica Vegetal, nenhum dos resultados foi satisfatório frente a normatização da Petrobras [21]. Uma análise conjunta dos resultados mostram que apenas o meio orgânico éster para as argilas organofilizadas com o tensoativo iônico Praepagen WB nos quatro teores normatizados, conduziu a resultados adequados frente a normatização da Petrobras [21].

\section{CONCLUSÕES}

O processo de hidrociclonagem controlado por difração a laser, fluorescência de raios $\mathrm{X}$ e difração de raios $\mathrm{X}$ evidenciou a eficiência do hidrociclone, sendo as melhores configurações A1, A2, B1 e B2, com supremacia da configuração A1; o processo de hidrociclonagem evidenciou a retirada dos acessórios e uma indesejável perda de finos; o inchamento de Foster no meio orgânico em parafina, éster e óleo diesel, evidenciou a maior afinidade com as argilas organofilizadas com o tensoativo Praepagen WB; os ensaios reológicos evidenciaram a supremacia da configuração A1 sobre as demais; as argilas organofilizadas com o tensoativo Praepagen WB e uso da bentonita no estado natural conduziram a uma reologia de acordo com as normas da Petrobrás, N-2258,1997B, enquanto que no conjunto $\mathrm{A} 1$, somente foram obtidos resultados adequados para quantidades mais elevadas de argilas (13,2 g). Para as demais configurações todos os resultados foram insatisfatórios; apenas o meio orgânico éster para as argilas organofilizadas com o tensoativo iônico Praepagen WB nos quatro teores normatizados, conduziu a resultados adequados frente a normatização da Petrobras; os dados reológicos obtidos com a organofilização das amostras com o tensoativo Imidazolina Oléica vegetal foram insatisfatórios frente as normas da Petrobrás [21].

\section{AGRADECIMENTOS}

Ao CNPq, à Oxiteno e à FINEP pelo auxilio financeiro.

\section{REFERÊNCIAS}

[1] P. Souza Santos, Tecnologia de argilas, Ed. Edgard Blücher, Vol. 1, S. Paulo, SP (1992) 350.

[2] A. R. V. Silva, H. C. Ferreira, Rev. Eletr. Mater. Proc. 3, 
3 (2008) 01.

[3] G. Lagaly, Clay Miner. 16 (1981) 1.

[4] F. R. Valenzuela Díaz, P. Souza Santos, H. L. Souza Santos, Quím. Ind. 42, 7 (1992) 33.

[5] R. W. Grimshaw, The chemistry and physics of clays, $4^{\text {th }}$ Ed., TechBooks, New York, EUA (1971).

[6] A. R. V. Silva, H. C. Ferreira, Rev. Eletr. Mater. Proc. 3, 2 (2008) 26.

[7] L. V. Amorim, Melhoria, proteção e recuperação da reologia de fluidos hidroargilosos para uso na perfuração de poços de petróleo, Tese Dr., Engenharia de Processos, UFCG, PB (2003).

[8] C. F. Gomes, Argilas: o que são e para que servem, $1^{\mathrm{a}}$ Ed., Fund. Calouste Gulbenkian, Lisboa, Portugal (1988) 160.

[9] R. Caenn, G. V. Chillingar, J. Petroleum Sci. Eng. 14 (1996) 221.

[10] J. F. Lee, M. M. Mortland, C. Tchiou, S. A. Boyd, Chem. Soc. Faraday Trans. 1 (1985) 2953.

[11] T. Permien, G. Lagaly, Colloid Polym. Sci. 272 (1990) 1306.

[12] F. R. Valenzuela Díaz, Quím. Ind. 42 (1992) 33.

[13] Y. H. Shen, Chemosphere 41 (2007) 711.

[14] Y. H. Shen, Chemosphere 44 (2001) 989.
[15] P. C. Yuang, Y. H. Shen, J. Colloid Interface Sci. 285 (2005) 443.

[16] H. S. Ferreira, Obtenção de argilas organofílicas purificadas para uso em fluidos de perfuração base óleo, Diss. Mestrado, Departamento de Engenharia de Materiais, UFCG, PB (2005).

[17] L. Svarovsky, Solid- liquid separation, $2^{\text {nd }}$ Ed., Butterworths, London, UK (2000) 568.

[18] M. D. Foster, Am. Miner. 38 (1953) 994.

[19] H. S. Ferreira, Otimização do processo de organofilização de bentonitas visando seu uso em fluidos de perfuração não aquosos, Tese Dr., Departamento de Engenharia de Materiais, UFCG, PB (2009).

[20] F. R. Valenzuela Díaz, Preparação, a nível de laboratório, de algumas argilas esmectíticas organofílicas, Tese Dr., Escola Politécnica, USP, S. Paulo, SP (1994).

[21] Petrobrás, Ensaio de argila organofílica para fluidos de perfuração à base de óleo, N-2259 (1997A).

[22] Petrobrás, Argila organofílica para fluidos de perfuração à base de óleo, N-2258 (1997B).

[23] L. F. A. Campos, Composições de argilas bentoníticas para utilização em fluidos de perfuração de poços de petróleo, Tese Dr., Engenharia de Processos, UFCG, PB (2007).

(Rec.07/07/2011, Rev. 16/08/2011, Ac. 16/10/2011) 